ARTICLE

DOI: $10.1038 / s 41467-018-04441-z$

\title{
A revised road map for the commitment of human cord blood CD34-negative hematopoietic stem cells
}

Keisuke Sumide (D) 1, Yoshikazu Matsuoka1, Hiroshi Kawamura1,2, Ryusuke Nakatsuka1, Tatsuya Fujioka1, Hiroaki Asano ${ }^{3}$, Yoshihiro Takihara ${ }^{4,5} \&$ Yoshiaki Sonoda ${ }^{1}$

We previously identified CD34-negative $\left(C D 34^{-}\right.$) severe combined immunodeficiency (SCID)-repopulating cells as primitive hematopoietic stem cells (HSCs) in human cord blood. In this study, we develop a prospective ultra-high-resolution purification method by applying two positive markers, CD133 and GPI-80. Using this method, we succeed in purifying single long-term repopulating $\mathrm{CD} 34^{-}$HSCs with self-renewing capability residing at the apex of the human HSC hierarchy from cord blood, as evidenced by a single-cell-initiated serial transplantation analysis. The gene expression profiles of individual $\mathrm{CD}_{3}{ }^{+}$and $\mathrm{CD} 34^{-} \mathrm{HSCs}$ and a global gene expression analysis demonstrate the unique molecular signature of $\mathrm{CD}_{3} 4^{-} \mathrm{HSCs}$. We find that the purified CD34- HSCs show a potent megakaryocyte/erythrocyte differentiation potential in vitro and in vivo. Megakaryocyte/erythrocyte progenitors may thus be generated directly via a bypass route from the CD34- HSCs. Based on these data, we propose a revised road map for the commitment of human CD34- $\mathrm{HSC}$ in cord blood.

\footnotetext{
${ }^{1}$ Department of Stem Cell Biology and Regenerative Medicine, Graduate School of Medical Science, Kansai Medical University, Hirakata 573-1010 Osaka, Japan. ${ }^{2}$ Department of Orthopedic Surgery, Kansai Medical University, Hirakata 573-1010 Osaka, Japan. ${ }^{3}$ School of Nursing, Kyoto Prefectural University of Medicine, Kyoto 602-8566 Kyoto, Japan. ${ }^{4}$ Department of Stem Cell Biology, Research Institute for Radiation Biology and Medicine, Hiroshima University, Hiroshima 734-8553 Hiroshima, Japan. ${ }^{5}$ Japanese Red Cross Osaka Blood Center, Osaka 536-0025 Osaka, Japan. Correspondence and requests for materials should be addressed to Y.S. (email: sonoda@hirakata.kmu.ac.jp)
} 
ematopoietic stem cells (HSCs) are a self-renewing population with the developmental potential to give rise to all types of mature blood cells ${ }^{1-3}$. It is well-documented that HSCs possess enormous therapeutic potential in the context of hematopoietic stem cell transplantation (HSCT) and regenerative medicine ${ }^{4-7}$. Recent advances in fluorescence-activated cell sorting (FACS) technology have enabled prospective isolation of murine HSCs to high purity using various cell surface markers, including CD34, Sca-1 and the SLAM family receptors ${ }^{8,9}$. Among them, the CD34 antigen has long been believed to be a reliable HSC marker in mammals ${ }^{10}$. Two decades ago, Nakauchi et al., however, challenged this long-standing dogma, showing that murine long-term (LT) lympho-myeloid reconstituting HSCs (LT-HSCs) are lineage negative $\left(\mathrm{Lin}^{-}\right), \mathrm{c}$-kit-positive $\left(\mathrm{c}-\mathrm{kit}^{+}\right)$, Sca-1-positive $\left(\mathrm{Sca}_{-}{ }^{+}\right)$and $\mathrm{CD}^{-} 4^{-}$low/negative $\left(\mathrm{CD} 34^{\text {low/- }}\right.$ ) (CD34 $\left.4^{\text {low/ }}-\mathrm{KSL}\right)$ cells $^{11}$. Furthermore, individual purified CD $34^{\text {low/ }}$ KSL cells were able to fully reconstitute lymphomyeloid hematopoiesis in recipient mice.

In contrast, the purification and isolation of bona fide human CD34- HSCs has lagged far behind the abovementioned murine $\mathrm{CD} 34^{\text {low/- }}{ }^{\mathrm{KSL}}$ cells ${ }^{11}$. However, a number of studies have suggested that human bone marrow (BM)-derived and cord blood (CB)-derived CD34 $4^{\text {low/- }}$ cell populations contain LT-HSCs ${ }^{12-14}$. Dick et al. developed a SCID-repopulating cell (SRC) assay to measure primitive human HSCs in a xenotransplantation setting with NOD/SCID mice ${ }^{15,16}$. Using this system, Bhatia et al. first reported that SRCs are present in human BM-derived and CBderived $\mathrm{Lin}^{-} \mathrm{CD}^{-} 4^{-}$cells ${ }^{17}$. However, the incidence of SRCs in $\mathrm{Lin}^{-} \mathrm{CD} 34^{-}$cells was reportedly very low $(1 / 125,000)$.

We previously identified very primitive CD34- SRCs in human $\mathrm{CB}$ using the intra-bone marrow injection (IBMI) method ${ }^{18}$ and proposed a new concept for the hierarchy in the human HSC compartment ${ }^{19,20}$. However, the incidence of CD34- SRC in 13 Lin $^{-}$CD $34^{-}$cells $(1 / 25,000)$ was still low ${ }^{18}$. We then developed a high-resolution purification method capable of enriching CD34SRCs at a $1 / 1000$ level in an $18 \mathrm{Lin}^{-} \mathrm{CD} 34^{-}$fraction $^{21}$. In addition, we further identified CD133 as a positive marker for CD34 ${ }^{-}$ as well as $\mathrm{CD}_{3}{ }^{+} \mathrm{SRCs}^{22}$, which can enrich $\mathrm{CD} 34^{+}$and CD34- ${ }^{-}$RCs at approximately $1 / 100$ and $1 / 140$ in $18 \mathrm{Lin}^{-}$ $\mathrm{CD}_{34}{ }^{+/} \mathrm{CD} 133^{+}$fractions, respectively ${ }^{20,22}$. Very recently, we demonstrated that the glycosylphosphatidylinositol-anchored protein GPI-80, which was originally reported to regulate neutrophil adherence and migration ${ }^{23,24}$, was also expressed on human full-term $\mathrm{CB}$-derived $18 \mathrm{Lin}^{-} \mathrm{CD} 34^{+} \mathrm{CD} 38^{-}$and $18 \mathrm{Lin}^{-}$ $\mathrm{CD}^{-} 4^{-}$cells $^{25}$. Interestingly, CB-derived CD34- SRCs were highly enriched in the $18 \mathrm{Lin}^{-} \mathrm{CD} 34^{-} \mathrm{GPI}-80^{+}$cell fraction at the $1 / 20$ level $^{25}$.

In this study, we combine two positive/enrichment markers, CD133 and GPI-80, in order to achieve ultra-high purification of $\mathrm{CD}_{3}{ }^{+}$and CD34- HSCs and successfully purify both SRCs at $1 / 5$ and $1 / 8$ cell levels, each of which turns out to be the highest purification levels to date. We then explore the biological nature of human CB-derived CD $34^{+}$and $\mathrm{CD} 34^{-}$SRCs (HSCs) to clarify the difference in their stem cell nature using single-cell-based in vivo transplantation and gene expression analyses. These detailed single-cell-based analyses allow us to distinguish human CB-derived $\mathrm{CD}_{3} 4^{+}$and $\mathrm{CD} 34^{-} \mathrm{HSCs}$ and map CD34 ${ }^{-}$HSCs at the apex of the human HSC hierarchy.

\section{Results}

Development of an ultra-high-resolution purification method. Using two positive markers CD $133^{22}$ and GPI- $80^{25}$, we developed an ultra-high-resolution purification method for isolating $\mathrm{CD} 34^{+}$ and CD34- ${ }^{-}$HSCs at the single-cell level (Fig. 1a-f). The 18Lin ${ }^{-}$ $\mathrm{CD}^{+}{ }^{+} \mathrm{CD} 38^{-} \mathrm{CD}^{-} 33^{+} \mathrm{GPI}-80^{+/-}$(R6 and R7) (abbreviated as $\left.34^{+} 38^{-} 133^{+} 80^{+/-}\right)$cells and the $18 \mathrm{Lin}^{-} \mathrm{CD} 34^{-} \mathrm{CD} 133^{+}$ GPI- $80^{+/-}$(R8 and R9) (abbreviated as $34^{-} 133^{+} 80^{+/-}$) cells were sorted for subsequent in vitro and in vivo experiments. Photomicrographs of the purified $34^{+} 38^{-} 133^{+} 80^{+/}$and $34^{-}$ $133^{+} 80^{+/-}$cells are shown in Fig. 1g. All cells showed immature blast-like morphologies. The area of the $34^{+} 38^{-} 133^{+} 80^{+/}-$cells was significantly larger than that of the $34^{-} 133^{+} 80^{+/}$cells (Fig. 1h).

In a separate set of experiment, we analyzed the expression patterns of CD90, CD49f, CD93 and CXCR4 on the surfaces of $18 \mathrm{Lin}^{-} \mathrm{CD}^{+} 4^{+} \mathrm{CD} 38^{-} \mathrm{CD} 133^{+} \mathrm{GPI}-80^{+}(\mathrm{R} 6)$ and $18 \mathrm{Lin}^{-} \mathrm{CD} 34^{-}$ $\mathrm{CD} 133^{+} \mathrm{GPI}-80^{+}(\mathrm{R} 8)$ cells using seven single-CB units. As shown in Supplementary Fig. 1, most $34^{+} 38^{-} 133^{+} 80^{+}$and $34^{-}$ $133^{+} 80^{+}$cells expressed CD90, CD49f and CXCR4. Approximately $70 \%$ of $34^{+} 38^{-} 133^{+} 80^{+}$cells expressed CD93; however, only a few $34^{-} 133^{+} 80^{+}$cells expressed CD93.

Megakaryocyte/erythrocyte differentiation potential of HSCs. The colony-forming capacity (CFC) of single sorted $\mathrm{CB}$-derived $34^{+} 38^{-} 133^{+} 80^{+1-}$ and $34^{-} 133^{+} 80^{+1-}$ cells was precisely analyzed in methylcellulose cultures (Fig. 1i, j). The plating efficiencies (PEs) of the $34^{+} 38^{-} 133^{+} 80^{+l-}$ and $34^{-} 133^{+} 80^{+l-}$ cells were 46 , 60,33 and $47 \%$, respectively. The PEs of $34^{+} 38^{-} 133^{+} 80^{-}$and $34^{-}$ $133^{+} 80^{-}$cells were significantly higher than those of $34^{+} 38^{-}$ $133^{+} 80^{+}$and $34^{-} 133^{+} 80^{+}$cells. Furthermore, the PEs of $34^{+}$ $38^{-} 133^{+}$cells were also significantly higher than those of $34^{-} 133^{+}$ cells regardless of GPI-80 expression. Interestingly, the $34^{-} 133^{+}$ $80^{+/-}$cells mainly formed CFU-EM colonies. Unexpectedly, $90 \%$ of colonies derived from $34^{-} 133^{+} 80^{-}$cells were CFU-EM (Fig. 1j), whereas the $34^{+} 38^{-} 133^{+} 80^{+/}$cells mainly formed CFU-Mix colonies (73 and 61\%). These results indicated that CFCs of human CB-derived $\mathrm{CD}_{3}{ }^{+}$and $\mathrm{CD} 34^{-}$HSCs are clearly different, and CD34- HSCs had a potent megakaryocyte/erythrocyte differentiation potential in vitro. Representative colonies and their constituent cells are shown in Supplementary Fig. 2.

Cell cycle status of $\mathrm{CD}^{+}{ }^{+}$and $\mathrm{CD}^{-}$HSCs. Most murine adult BM-derived HSCs are known to be cell cycle dormant ${ }^{26}$. However, murine fetal HSCs derived from the AGM (aortagonad-mesonephros), placenta and fetal liver are largely cycling $^{26}$. In contrast to extensive studies on murine HSCs, the cell cycle status of human primitive HSCs has not been fully elucidated. Human BM-derived $\mathrm{CD} 34^{+} \mathrm{CD} 38^{-}$cells containing primitive LT-HSCs have been reported to be cell cycle dormant $^{27,28}$. However, the cell cycle status of human CB-derived primitive HSCs remains unclear. Therefore, it is necessary to validate the reported findings of murine HSCs in the human HSC hierarchy. In such efforts, it is critical to use a highly purified human HSC population for investigating the cell cycle status/ dormancy, as contamination with committed progenitors in the HSC population would hamper the accurate determination of the cell cycle status. As shown in this study, $34^{+} 38^{-} 133^{+} 80^{+}$and $34^{-} 133^{+} 80^{+}$cells, which showed high incidences of $\mathrm{CD} 34^{+}$and CD34- ${ }^{-}$RCs (HSCs), provided robust multi-lineage human cell repopulation at 20 weeks after transplantation and efficient engraftment upon the secondary transplantation.

We therefore investigated the proportions of CD34 ${ }^{+}$and CD34 - SRCs (HSCs) in each cell cycle phase using the abovementioned $34^{+} 38^{-} 133^{+} 80^{+/-}$(R6 and R7 in Fig. 1e) and $34^{-} 133^{+} 80^{+/-}$ (R8 and R9 in Fig. 1f) cells via the Ki-67/7-AAD staining method. As shown in Supplementary Fig. 3a, approximately 30 to $40 \%$ of the cells in the $34^{+} 38^{-} 133^{+} 80^{+1-}$ fractions were in $\mathrm{G}_{0}$ phase of the cell cycle, and $<1 \%$ of cells in $S-G_{2}-M$ phase. Approximately 50 to $60 \%$ of the cells in the $34^{-} 133^{+} 80^{+/}$fractions were in $\mathrm{G}_{0}$ phase of the cell cycle, and $<1 \%$ of cells in $S-G_{2}-M$ phase. In 


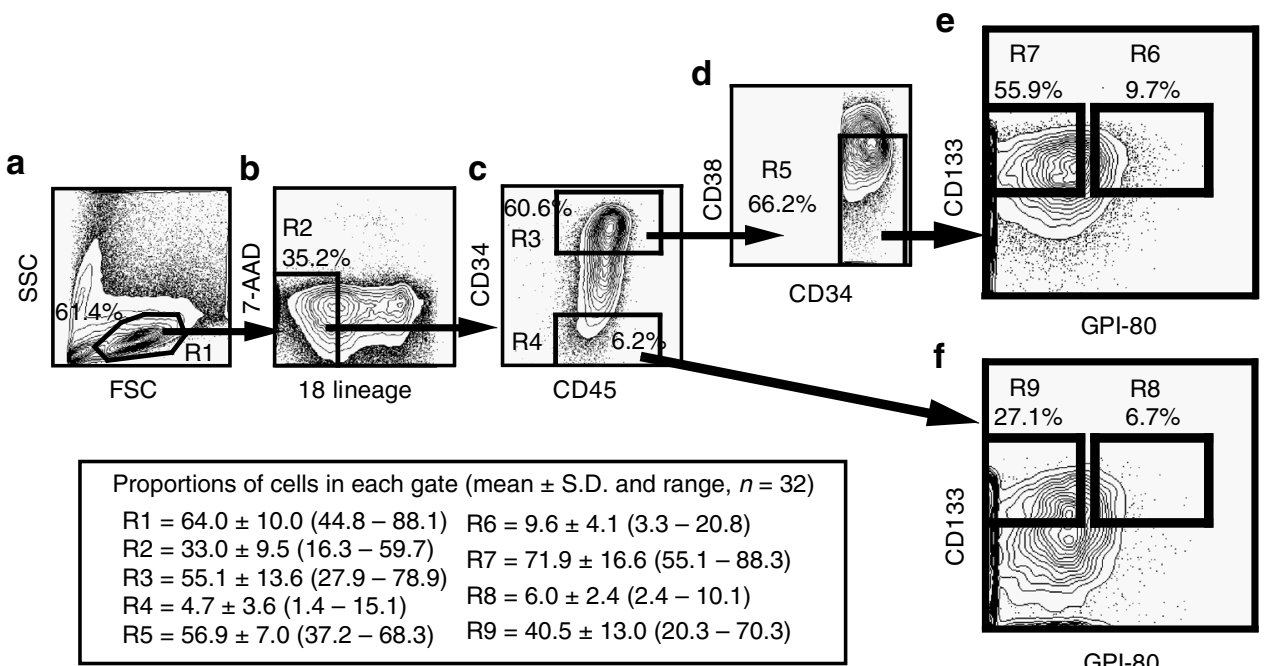

GPI-80
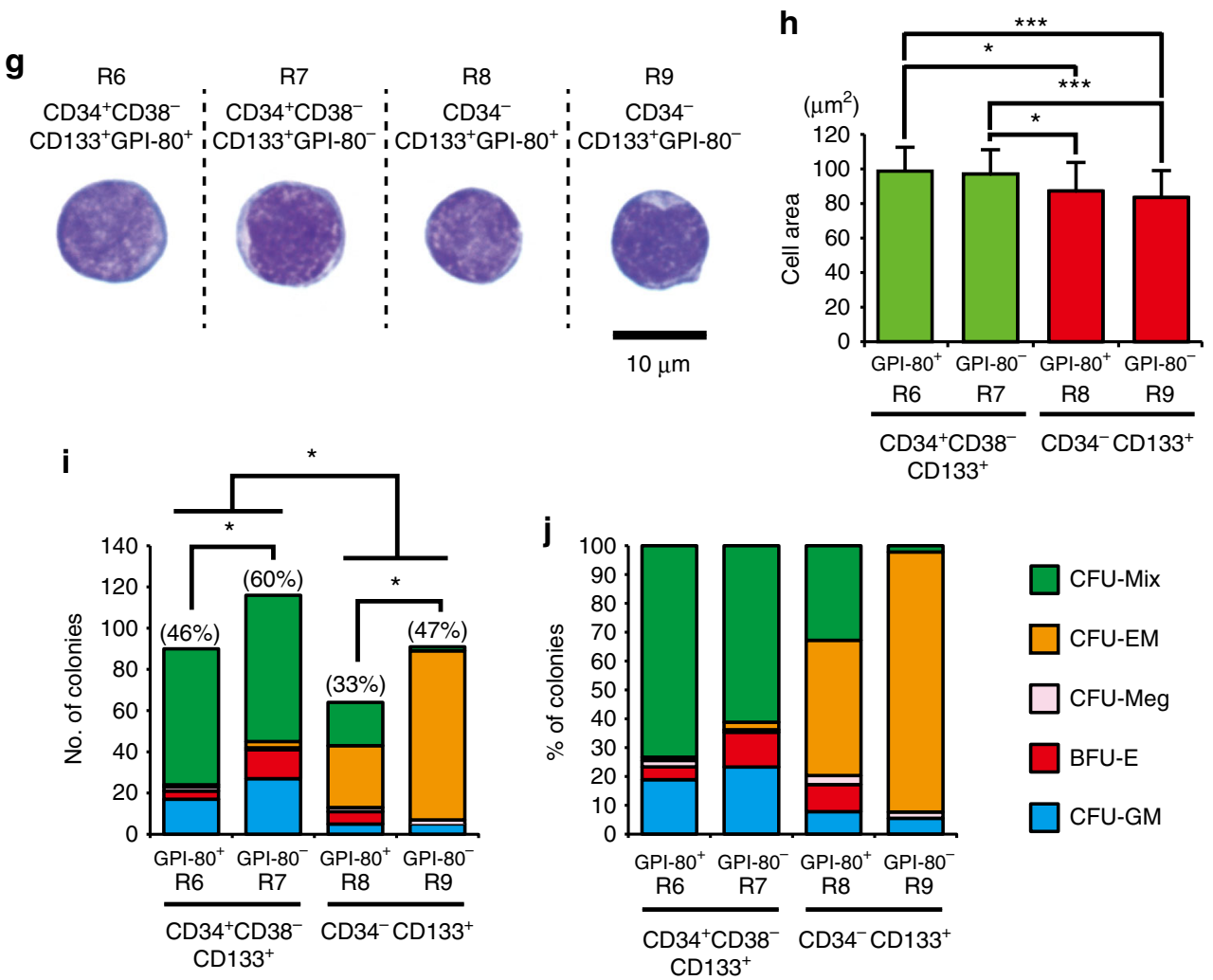

Fig. 1 Representative FACS profile and colony-forming capacity of highly purified CB-derived $18 \mathrm{Lin}^{-} \mathrm{CD} 34^{+} \mathrm{CD} 38^{-} \mathrm{CD} 133^{+} \mathrm{GPI}-80^{+/-}$and $18 \mathrm{Lin}{ }^{-} \mathrm{CD} 34$ ${ }^{-}$CD133 ${ }^{+} \mathrm{GPI}-80^{+/-}$cells. A representative FACS profile is shown. a The forward scatter/side scatter (FSC/SSC) profile of immunomagnetically separated $\mathrm{Lin}^{-}$cells. The R1 gate was set on the blast-lymphocyte window. $\mathbf{b}$ The R2 gate was set on the 18Lin ${ }^{-}$living cells. $\mathbf{c}$ The R2 gated cells were subdivided into two fractions: $18 \mathrm{Lin}^{-} \mathrm{CD} 45^{+} \mathrm{CD} 34^{+}$(R3) and CD34-(R4) cells, according to their expression of CD34. The definitions of CD34 ${ }^{+/-}$cells are as follows: the $\mathrm{CD}_{4} 4^{+}$fraction contains cells expressing $>5 \%$ of the maximum BV421 fluorescence intensity (FI). The CD34- level of $\mathrm{FI}$ was determined based on the Fluorescence Minus One controls. d The cells residing in the R3 gate were further subdivided into $18 \mathrm{Lin}^{-} \mathrm{CD} 45^{+} \mathrm{CD} 34^{+} \mathrm{CD} 38^{-}(\mathrm{R} 5)$ cells. The $\mathrm{CD} 38^{-}$ fraction contains cells expressing $<10 \%$ of the maximum PE-Cy7 Fl. e The R5-gated cells were further subdivided into two fractions: 18 Lin ${ }^{-} \mathrm{CD} 45^{+} \mathrm{CD}^{2} 4$ ${ }^{+} \mathrm{CD}_{38}{ }^{-} \mathrm{CD} 133^{+} \mathrm{GPI}-80^{+}$(R6) and GPI-80-(R7) cells according to their expression of CD133 and GPI-80. $\mathbf{f}$ The R4-gated cells were further subdivided into two fractions: $18 \mathrm{Lin}^{-} \mathrm{CD} 45^{+} \mathrm{CD} 34^{-} \mathrm{CD} 133^{+} \mathrm{GPI}-80^{+}$(R8) and GPI-80-(R9) cells. The definitions of $\mathrm{CD} 133^{+/-}$and $\mathrm{GPI}-80^{+/-}$cells are the same as reported 22,25 . The phenotypic purity of the R6 and R8 sorted cells consistently exceeded $99 \%$. Detailed FCM data, including numbers of experiments, and mean \pm S.D. and ranges of proportions of cells in each gate, are depicted in the figure. $\mathbf{g}$ Cells sorted from the R6 to R9 fractions were cytospun on to the slide glasses and stained with May-Grunwald-Giemsa. $\mathbf{h}$ The areas of the R6 to R9 cells were analyzed using the Image J software program (mean \pm S.D., $n$ $=33$ cells/group, ${ }^{*} p<0.05,{ }^{\star \star \star} p<0.001$, Tukey's multiple comparison procedure). $\mathbf{i}$ Single-cell CFCs of sorted R6 to R9 cells. The plating efficiency (PE) is shown in parentheses (mean \pm S.D., 196 cells/group, ${ }^{\star} p<0.05$, two-way analysis of variance). $\mathbf{j}$ The percentages of various types of colonies are shown. CFU-Mix (green bar), CFU-EM (orange bar), CFU-Meg (pink bar), BFU-E (red bar) and CFU-GM (blue bar) 
contrast, $>90 \%$ of human BM-derived $34^{+} 38^{-} 133^{+} 80^{+/-}$cells were in $G_{0}$ phase of the cell cycle (Supplementary Fig. 3b). As controls, we simultaneously investigated the cell cycle status of $\mathrm{CB}-$ and $\mathrm{BM}$-derived $\mathrm{CD}^{-} 4^{+} \mathrm{CD}^{-} 8^{-} \mathrm{CD}^{-} 0^{+} \mathrm{HSCs}\left(\mathrm{CD} 90^{+}\right.$ HSCs), CD $34^{+} \mathrm{CD}_{38}{ }^{-} \mathrm{CD}^{-}{ }^{-} \mathrm{CD} 45 \mathrm{RA}^{-}$cells (MPPs), CD $34^{+}$ $\mathrm{CD}_{3}{ }^{-} \mathrm{CD}^{-}{ }^{-} \mathrm{CD} 45 \mathrm{RA}^{+}$cells (MLPs) and $\mathrm{CD} 34^{+} \mathrm{CD} 38^{\text {high }}$ hematopoietic progenitor cells (HPCs) (Supplementary Fig. 3c-e). The purification methods of these target cells are shown in Supplementary Fig. 3c. As shown in Supplementary Figs. $3 \mathrm{~d}$ and e, the proportions of $\mathrm{CB}$-derived CD34 ${ }^{+} \mathrm{HSC} / \mathrm{HPCs}$ in the $\mathrm{G}_{0}$ phase was $<40 \%$. The proportion of cells in the $\mathrm{G}_{0}$ phase gradually decreased in accordance with the differentiation status (Supplementary Fig. 3d and e). In contrast, the proportion of BMderived CD90 ${ }^{+}$HSCs in the $\mathrm{G}_{0}$ phase was $>90 \%$ (Supplementary Figs. 3d and e). And the proportions of MPPs, MLPs and $\mathrm{CD} 34^{+} \mathrm{CD} 38^{\text {high }}$ HPCs in the $\mathrm{G}_{0}$ phase were about 80,70 and $30 \%$, respectively. The cell cycle status of $\mathrm{BM}$-derived $\mathrm{CD} 34^{+}$ HSCs was consistent with the findings of the previous reports $^{27,28}$. However, the cell cycle status of the CB-derived $\mathrm{CD}_{3}{ }^{+}$and $\mathrm{CD} 34^{-}$HSCs in the present study was different from the previously reported $\mathrm{data}^{29}$. The $\mathrm{CB}$-derived $\mathrm{CD}_{3}{ }^{+}$and CD34- ${ }^{-}$SRCs (HSCs) seemed to be in a greater cycling flux than previously estimated ${ }^{29}$. This is not very surprising, as CB-derived primitive $\mathrm{CD} 34^{+}$and $\mathrm{CD} 34^{-}$HSCs may reflect fetal hematopoiesis $^{30-32}$.

In order to validate the dormancy of $\mathrm{CB}$-derived $\mathrm{CD}_{3}{ }^{+}$and CD34- ${ }^{-}$RCs (HSCs), we performed a single-cell proliferation assay. As shown in Supplementary Fig. 4a, single $34^{+} 38^{-} 133^{+} 80$ + and $34^{-} 133^{+} 80^{+}$cells began to divide after $48 \mathrm{~h}$ of culture with basal medium containing SCF + TPO. Half of these cells completed their first cell division by $96 \mathrm{~h}$ of culture. In contrast, almost all of the $18 \mathrm{Lin}^{-} \mathrm{CD} 34^{+} \mathrm{CD} 38^{\text {high }}$ cells completed their first cell division by $48 \mathrm{~h}$ of culture. In the culture with complete medium containing 10\% FCS and 7 cytokines (SCF, TPO, FL, IL3 , IL-6, GM-CSF and G-CSF), almost all of the three classes of HSCs/HPCs completed their first cell division by $96 \mathrm{~h}$ of culture (Supplementary Fig. 4b). Among the three classes of HSCs/HPCs, the $\mathrm{CD} 34^{+} \mathrm{CD} 38^{\text {high }}$ cells (HPCs) most rapidly proliferated, and the $34^{-} 133^{+} 80^{+}$cells (CD34- $4^{-}$SCs) most slowly proliferated. We then determined how long it took for these three classes of HSCs/HPCs to complete the first cell division (time to complete first cell division, $T_{\mathrm{fcd}}$ ) (Supplementary Fig. $4 \mathrm{c}$ ). The $T_{\mathrm{fcd}}$ of both the $34^{+} 38^{-} 133^{+} 80^{+}$and $34^{-} 133^{+} 80^{+}$cells were approximately $70 \mathrm{~h}$ in the basal medium. This was significantly longer than the $T_{\text {fcd }}(40 \mathrm{~h})$ of the $18 \mathrm{Lin}^{-} \mathrm{CD} 34^{+} \mathrm{CD} 38^{\text {high }}$ cells. The $T_{\mathrm{fcd}}$ of the two classes of HSCs was significantly shorter in the complete medium than in the basal medium. Interestingly, the time to complete second cell division ( $T_{\mathrm{scd}}$ ) of all 3 classes of HSCs/HPCs ranged from 20 to $30 \mathrm{~h}$, regardless of the culture media (Supplementary Fig. 4d). These results suggest that both primitive $\mathrm{CD}^{+}{ }^{+}$and CD34 ${ }^{-}$HSCs and committed HPCs begin to divide in the same fashion once they start their proliferation in cultures.

Combination of CD133 and GPI-80 for purification of HSCs. We performed a limiting dilution analysis (LDA) to determine the frequencies of $\mathrm{CD}_{3} 4^{+}$and $\mathrm{CD} 34^{-}$SRCs in the abovementioned four-cell fractions (R6 to R9 in Fig. 1). As shown in Supplementary Fig. 5 and Supplementary Data 1, the frequencies of SRCs in the $34^{+} 38^{-} 133^{+} 80^{+}$and $34^{-} 133^{+} 80^{+}$cells were $1 / 4.9$ and $1 /$ 8.1 cells, respectively, each of which is the highest frequency of CB-derived $\mathrm{CD} 34^{+}$and $\mathrm{CD} 34^{-}$SRCs to date. The frequencies of SRCs in $34^{+} 38^{-} 133^{+} 80^{-}$and $34^{-} 133^{+} 80^{-}$cells were $1 / 51.3$ and $1 / 49.8$ cells, respectively. Based on these LDA data, we next analyzed the LT-repopulating capacity of the two classes of HSCs residing in the $34^{+} 38^{-} 133^{+} 80^{+}$and $34^{-} 133^{+} 80^{+}$cells.
Primary and secondary repopulating capacities of HSCs. Next, $20034^{+} 38^{-} 133^{+} 80^{+}$cells (referred to as CD34 ${ }^{+}$SRCs/HSCs) containing 41 SRCs $(n=25)$ and $20034^{-} 133^{+} 80^{+}$cells (referred to as $\mathrm{CD}^{-} 4^{-}$SRCs/HSCs) containing 25 SRCs $(n=23)$ were transplanted into NOG mice by IBMI (Fig. 2a; Supplementary Data 2a). All of the primary recipient mice showed signs of human cell repopulation at 12 weeks after transplantation. The repopulation levels were maintained until 20 to 22 weeks after transplantation (Fig. 2b). Both the $\mathrm{CD}_{4}{ }^{+}$and $\mathrm{CD}_{3}{ }^{-}$SRCs showed multi-lineage reconstitution abilities in the BM, peripheral blood (PB), spleen and thymus (Fig. 2d, e; Supplementary Data 2b).

We then performed secondary transplantation. Most of the secondary recipient NOG mice that received $1 / 5$ of whole BM cells from the primary engrafted recipient mice showed distinct multi-lineage reconstitution (Fig. 2c, Supplementary Data 2a and $2 \mathrm{c}$ and Supplementary Fig. 6). Furthermore, in each 10 primary recipient mice that received $20034^{+} 38^{-} 133^{+} 80^{+}$cells or $20034^{-}$ $133^{+} 80^{+}$cells, we resorted $18 \mathrm{Lin}^{-} \mathrm{CD} 34^{+}$and $18 \mathrm{Lin}^{-} \mathrm{CD} 34^{-}$ cells from the primarily engrafted mouse BM and transplanted these cells into the secondary ones. As shown in Supplementary Data $2 \mathrm{a}$, in the case of $\mathrm{CD} 34^{+}$SRCs, 6 out of 10 mice that received resorted $18 \mathrm{Lin}^{-} \mathrm{CD}_{3} 4^{+}$cells showed multi-lineage human cell repopulation. However, none of the 10 mice that received 18 $\mathrm{Lin}^{-} \mathrm{CD} 34^{-}$cells were repopulated with human cells. These results clearly indicated that $\mathrm{CD} 34^{+}$SRCs were able to maintain (self-renew) CD34 ${ }^{+}$SRCs but could not generate CD34 SRCs in vivo, as we reported previously ${ }^{18}$. In contrast, in the case of $\mathrm{CD}^{-} 4^{-}$SRCs, 6 out of 10 mice that received resorted $18 \mathrm{Lin}^{-} \mathrm{CD}^{+} 4^{+}$cells showed multi-lineage human cell repopulation. These results clearly indicated that $\mathrm{CD} 34^{-}$SRCs were able to generate $\mathrm{CD} 34^{+}$SRCs in vivo, as we reported previously ${ }^{18,33}$. Very interestingly, 4 out of 10 mice that received $18 \mathrm{Lin}^{-} \mathrm{CD}^{-} 4^{-}$cells resorted from primary recipient mice that received $34^{-} 133^{+} 80^{+}$cells showed multi-lineage human cell reconstitution (Supplementary Fig. 7). These observations suggest that $\mathrm{CD} 34^{-}$SRCs were able to self-renew in NOG mice.

Lineage differentiation potential of HSCs in vivo. Next, we precisely analyzed the multi-lineage differentiation potentials of $\mathrm{CD}_{4}^{+}$and $\mathrm{CD}^{-} 4^{-}$SRCs in various organs, including the BM, $\mathrm{PB}$, spleen and thymus, in the abovementioned primary recipient NOG mice that received $20034^{+} 38^{-} 133^{+} 80^{+}$or $34^{-} 133^{+} 80^{+}$ cells (Supplementary Data 2b). As shown in Supplementary Fig. $8 \mathrm{a}$, the human $\mathrm{CD} 45^{+}$cell repopulation capacities of both CD $34^{+}$and $\mathrm{CD}^{-} 4^{-}$SRCs were not statistically different. These data were consistent with our previously reported data $18,21,22,25,33$. However, the differentiation potentials of these $\mathrm{CD}_{4}{ }^{+}$and $\mathrm{CD} 34^{-}$SRCs with regard to CD $19^{+}$lymphoid cells were clearly different. These CD $34^{+}$SRCs showed repopulation of $\mathrm{CD} 19^{+}$cells at significantly higher levels than CD34- SRCs in the left tibia (injected site) and PB (Supplementary Fig. 8a(iv)), which is consistent with our previous report ${ }^{34}$. Very interestingly, these CD34- SRCs showed significantly higher levels of CD41 ${ }^{+}$ cells than $\mathrm{CD}_{3} 4^{+}$SRCs in the left tibia (injected site) and spleen (Supplementary Fig. 8a(vi)). Furthermore, these CD34- SRCs also showed significantly higher levels of $\mathrm{CD}_{235 \mathrm{a}^{+}}$cells than CD34 ${ }^{+}$SRCs in the left tibia (injected site) and other bones (Supplementary Fig. 8a(vii)). These results demonstrated that CD34- ${ }^{-}$SRCs (HSCs) possess more potent megakaryocyte/ erythrocyte differentiation potential in vivo than $\mathrm{CD}_{3} 4^{+}$SRCs (HSCs).

We then precisely analyzed the multi-lineage differentiation potentials of $\mathrm{CD}_{3}{ }^{+}$and CD34- ${ }^{-}$SRCs in secondary transplantations (Supplementary Data 2c). As shown in Supplementary 
a
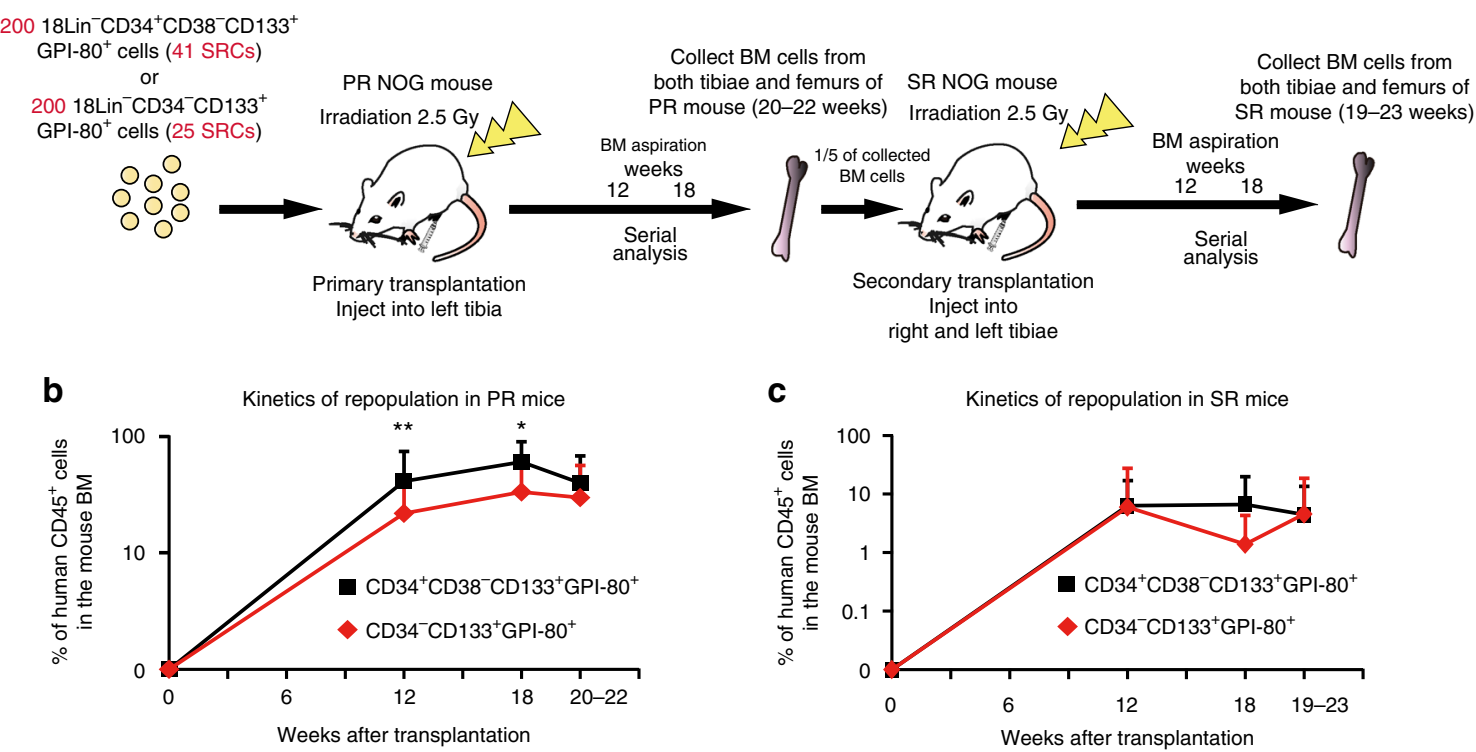

d

18 Lin $^{-} \mathrm{CD} 34^{+} \mathrm{CD} 38^{-} \mathrm{CD} 133^{+} \mathrm{GPI}-80^{+}$cells (CD34 $\left.{ }^{+} \mathrm{SRC}\right)$
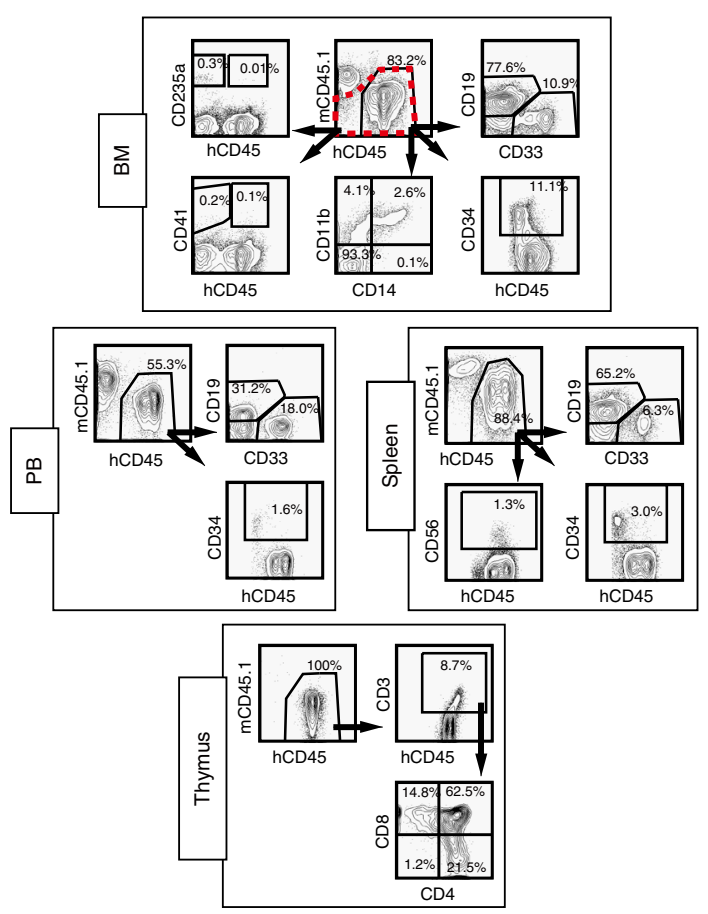

$\mathbf{e}$

$18 \mathrm{Lin}^{-} \mathrm{CD} 34^{-} \mathrm{CD} 133^{+} \mathrm{GPI}-80^{+}$cells (CD34- $\mathrm{SRC})$
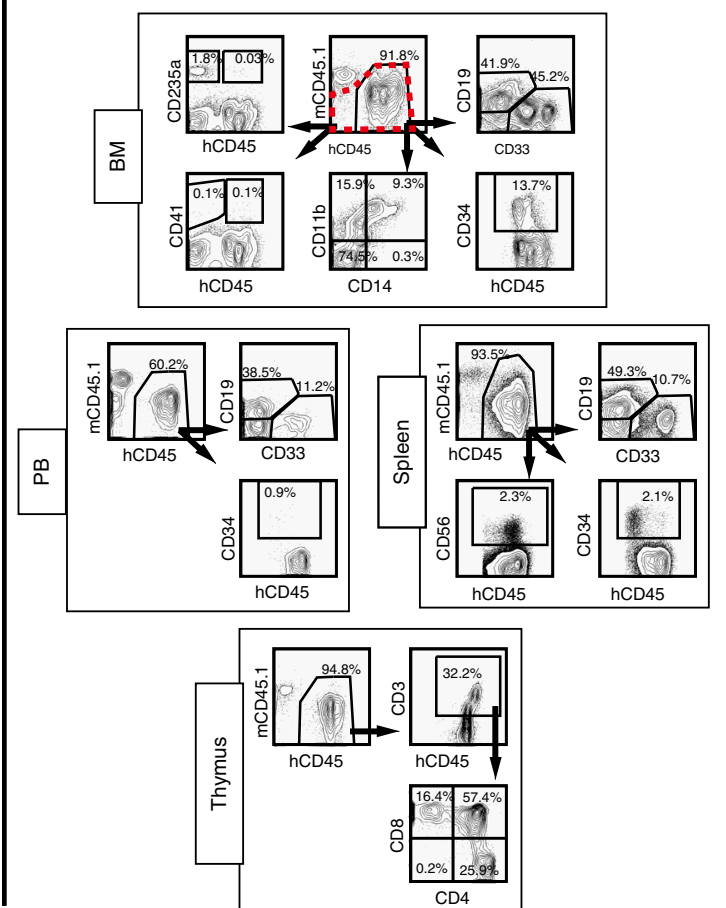

Fig. 2 SCID-repopulating cell activity and serial analyses of human cell repopulation of $18 \mathrm{Lin}^{-} \mathrm{CD} 4^{+} \mathrm{CD}^{-} 8^{-} \mathrm{CD} 133^{+} \mathrm{GPI}-80^{+}$and $18 \mathrm{Lin}^{-} \mathrm{CD} 34^{-} \mathrm{CD} 133$ ${ }^{+} \mathrm{GPI}-80^{+}$cells in primary and secondary NOG mice by IBMI. a A schematic illustration of primary and secondary transplantation of CD34 ${ }^{+}$and $\mathrm{CD}^{-} 4^{-}$ SRCs is shown. PR, primary recipient; SR, secondary recipient. b The long-term repopulating potential of the CD34+ and CD34- SRCs was determined by serially analyzing the kinetics of BM engraftment for 20 to 22 weeks in primary NOG mice that received transplants of 20018 Lin $^{-}$CD34 ${ }^{+} \mathrm{CD}^{-} 8^{-} \mathrm{CD}^{-} 33$ ${ }^{+} \mathrm{GPI}-80^{+}$cells (41 SRCs) $(n=25)$ and $20018 \mathrm{Lin}^{-} \mathrm{CD} 34^{-}{ }^{-} \mathrm{CD} 133^{+}{ }^{-\mathrm{GPI}}-80^{+}$cells $(25 \mathrm{SRCs})(n=23)$, respectively. All of the primary recipient mice were highly repopulated with human $\mathrm{CD} 45^{+}$cells. The human $\mathrm{CD} 45^{+}$cell repopulation rates of the mice that were transplanted with $\mathrm{CD} 34^{+} \mathrm{SRCs}$ at 12 and 18 weeks after transplantation were significantly higher than those of the mice that were transplanted with CD34- SRCs. However, the repopulation rates of both mice were comparable at 20 to 22 weeks after transplantation (mean \pm S.D., ${ }^{\star} p<0.05,{ }^{\star \star} p<0.01$, two-tailed Student's $t$-test). c The kinetics of human $\mathrm{CD}_{4} 5^{+}$cell reconstitution in secondary recipient NOG mice that received $1 / 5$ of whole BM cells from the abovementioned primary recipient mice. The repopulation rates of both mice ( $n=17$ for CD34+ SRCs and $n=15$ for CD34- SRCs) were comparable during the observation period (12 to 23 weeks after transplantation) (there were no significant differences between both group, two-tailed Student's $t$-test). d, e Both of the CD34 ${ }^{+}$and CD34 $^{-}$SRCs showed multi-lineage reconstitution abilities in primary recipient mice, including CD34 ${ }^{+}$stem/progenitor cells, CD19+ ${ }^{+}$-lymphoid, CD33+ and $\mathrm{CD}^{+} 1 \mathrm{~b}^{+}$ myeloid, $\mathrm{CD}_{14}{ }^{+}$monocytic, $\mathrm{CD} 235 \mathrm{a}^{+}$erythroid and $\mathrm{CD} 41^{+}$megakaryocytic cells. The presence of $\mathrm{CD} 235 \mathrm{a}^{+}$and $\mathrm{CD} 41^{+}$cells was analyzed using human $\mathrm{CD}_{4} 5^{+/}$- cell gate (depicted by red dotted lines). We also detected CD56 ${ }^{+}$NK cells in the spleen and CD3 ${ }^{+}$and CD4/CD8 single/double-positive cells in the thymus. Most of the engrafted primary recipient mice showed distinct multi-lineage secondary reconstitution abilities. Detailed FCM data, including numbers of experiments, means and ranges of proportions of cells in each cell lineage are shown in Supplementary Fig. 8a, Supplementary Data 2a and b 
Fig. $8 \mathrm{~b}$, the human $\mathrm{CD} 45^{+}$cell repopulation capacities of $\mathrm{CD} 34^{+}$ and $\mathrm{CD}_{3}{ }^{-}$SRCs were not statistically different. These CD34SRCs, however, showed significantly higher levels of $\mathrm{CD} 34^{+}$cells than $\mathrm{CD}_{34}{ }^{+}$SRCs in the both tibiae (injected site) and other bone (Supplementary Fig. 8b(ii)). These results suggest that CD34 - SRCs are a more immature class of HSCs than CD34 ${ }^{+}$SRCs.

Repopulating capacities of single $\mathrm{CD}_{34}^{+}$and $\mathrm{CD}^{-}{ }^{-}$HSCs. To validate the definitive stem cell nature, such as self-renewal activity and multi-lineage differentiation capacity of human primitive $\mathrm{CD}_{3}{ }^{+}$and CD34- ${ }^{-}$SRs (HSCs), we performed a singlecell transplantation analysis with highly purified $34^{+} 38^{-} 133^{+} 80^{+}$ and $34^{-} 133^{+} 80^{+}$cells. In the first set of experiments (Supplementary Data $3 a), 3$ out of $57(5.3 \%)$ or 2 out of $78(2.6 \%)$ recipient NOG mice that received single $34^{+} 38^{-} 133^{+} 80^{+}$or 34 ${ }^{-} 133^{+} 80^{+}$cells showed multi-lineage human cell repopulation. As shown in Supplementary Data $3 a$ and b, 7 out of $62(11.3 \%)$ and 6 out of $100(6.0 \%)$ recipient NSG mice that received single $34^{+} 38^{-} 133^{+} 80^{+}$or $34^{-} 133^{+} 80^{+}$cells showed multi-lineage human cell repopulation, with repopulation rates of $0.8 \%-45.1 \%$ or $0.9 \%-30.1 \%$ in the injected left tibiae, respectively. Notably, even single-cell purified human CB-derived CD34SRCs were able to be engrafted in recipient NOG/NSG mice; to our knowledge, this is the first time this has been reported. We then precisely analyzed their multi-lineage reconstitution abilities in the BM, PB and spleen, as shown in Fig. 3 and Supplementary
Data 3b. These results confirmed that both of the $\mathrm{CD}_{3} 4^{+}$and CD $34^{-}$SRCs had multi-lineage differentiation capability. In addition, engraftment of single $34^{+} 38^{-} 133^{+} 80^{+}$and $34^{-} 133^{+} 80$ + cells provided clear evidence that human $\mathrm{CB}$-derived primitive $\mathrm{CD}^{+} 4^{+}$and CD34- ${ }^{-}$RCs (HSCs) expressed CD133 and GPI-80.

Evidence for the in vivo self-renewing capacities of HSCs. We next performed secondary transplantation with whole BM cells from engrafted primary recipient mice that received single purified $\mathrm{CD}_{3}{ }^{+}$and $\mathrm{CD} 34^{-}$SRCs. Five out of nine mice receiving CD34 ${ }^{+}$SRCs and five out of eight mice receiving CD34- ${ }^{-}$SRCs showed distinct secondary multi-lineage human cell repopulations (Supplementary Data 3a). Of note, one NSG mouse $\left(34^{+}\right.$ NSG046) that received a single $34^{+} 38^{-} 133^{+} 80^{+}$cell showed robust human $\mathrm{CD}_{4} 5^{+}$cell repopulation even at 22 weeks after transplantation (Supplementary Data 3a). We transplanted 2/5 whole BM cells into two secondary recipient NSG mice. Both mice showed lympho-myeloid reconstitution by 12 to 22 weeks after transplantation (Supplementary Fig. 9a and b, and Supplementary Data 3c). The patterns of multi-lineage repopulation observed in the two secondary recipient mice were not equivalent. Notably, four out of six NSG mice that received a single $34^{-} 133$ ${ }^{+} 80^{+}$cell showed robust human $\mathrm{CD} 45^{+}$cell repopulation at 20 to 24 weeks after transplantation (Supplementary Data 3a). We then transplanted $2 / 5$ whole BM cells of each engrafted primary recipient mice into two secondary recipient NSG mice. Surprisingly, a
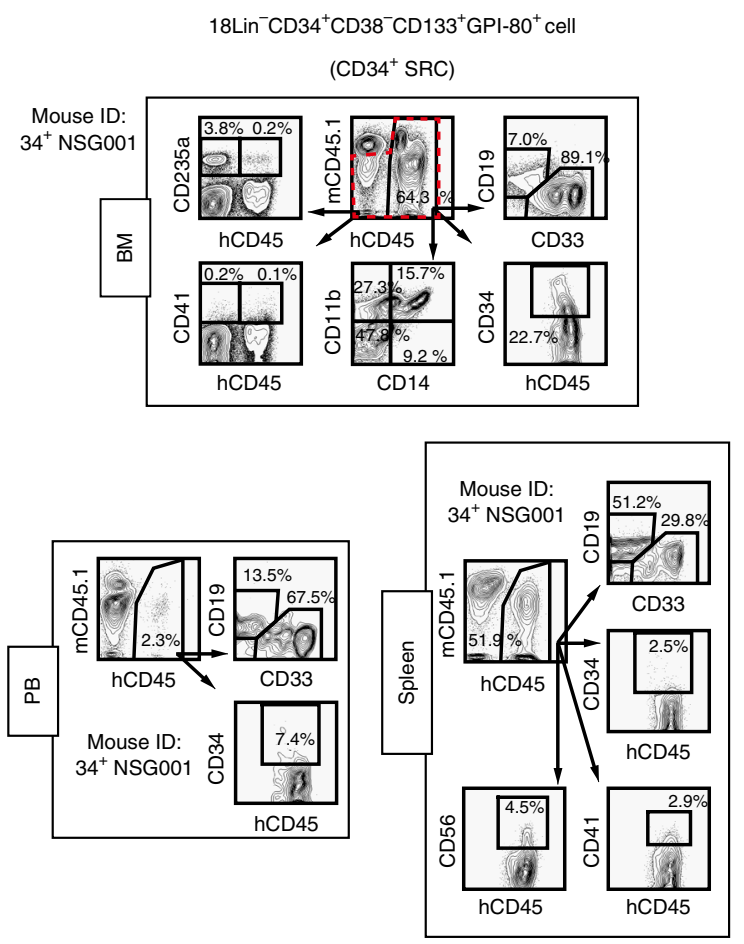

b
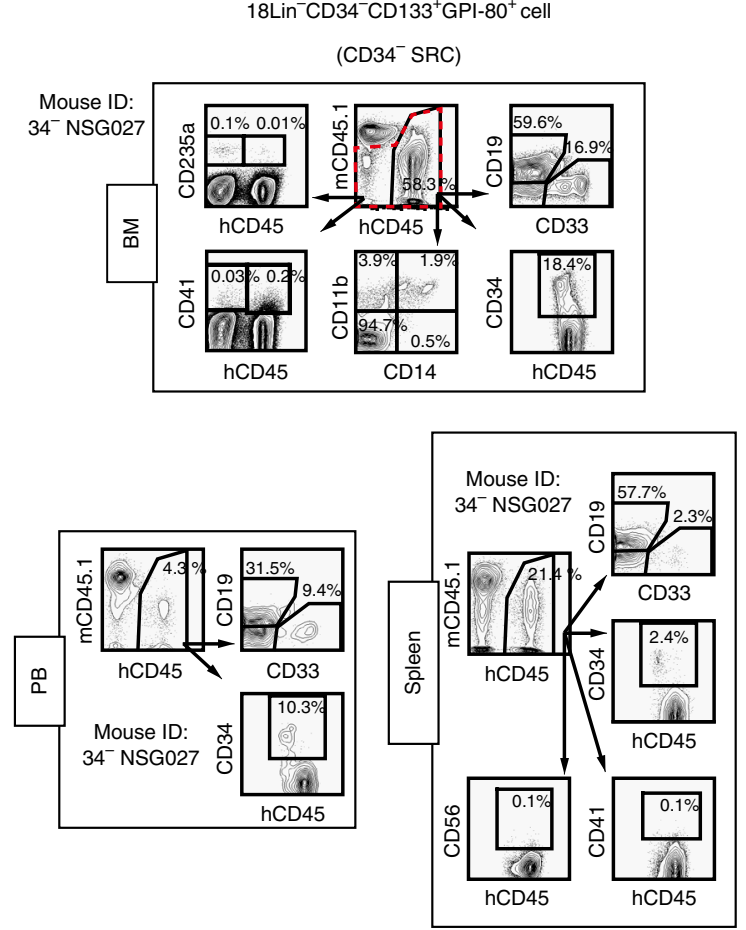

Fig. 3 Human multi-lineage hematopoietic repopulation abilities of single CD34 ${ }^{+}$and CD34- SRCs. Human multi-lineage hematopoietic repopulations in the primary recipient NSG mice that received a single $18 \mathrm{Lin}^{-} \mathrm{CD} 34^{+}{ }^{\mathrm{CD}} 38^{-} \mathrm{CD} 133^{+} \mathrm{GPI}-80^{+}$(Mouse ID: $34^{+} \mathrm{NSG001}$ ) or b single $18 \mathrm{Lin}{ }^{-} \mathrm{CD} 34^{-} \mathrm{CD} 133$ ${ }^{+} \mathrm{GPI}-80^{+}$(Mouse ID: $34^{-}$NSG027) cells were analyzed by 6-color FCM at 22 or 21 weeks after transplantation. The expression of CD19, CD33 CD34 (BM, PB and spleen), CD11b and CD14 (BM), CD41 (BM and spleen), CD235a (BM) and CD56 (spleen) in living human CD45 ${ }^{+}$cells was analyzed. The presence of $\mathrm{CD}_{4} 1^{+}$and $\mathrm{CD} 235 \mathrm{a}^{+}$cells in $\mathrm{BM}$ was analyzed using a human $\mathrm{CD} 45^{+/}$cell gate (depicted by red dotted lines). The mouse ID numbers presented in the figure corresponded those listed in Supplementary Data 3a. Analyses of the BM (other bones), PB and spleens of the two representative mice that received either $\mathrm{CD} 34^{+}$SRC $\mathbf{a}$ or $\mathrm{CD} 34^{-}$SRC $\mathbf{b}$ revealed that both SRCs had an in vivo differentiation capacity comparable to that of $\mathrm{CD} 34^{+}$ stem/progenitor cells, CD19 ${ }^{+}$B-lymphoids, $\mathrm{CD}_{3}{ }^{+} / \mathrm{CD}_{11 b^{+}}$myeloids, CD14 ${ }^{+}$monocytes, CD235a ${ }^{+}$erythroid and $\mathrm{CD} 41^{+}$megakaryocytic lineages. $\mathrm{CD} 56$ + NK cells were detected in the spleen. These results confirmed that both $\mathrm{CD}_{3} 4^{+}$and $\mathrm{CD} 34^{-} \mathrm{SRC}$ s had definite multi-lineage differentiation potential. Detailed FCM data of all recipient mice that received single $\mathrm{CD}_{3} 4^{+}$and $\mathrm{CD} 34^{-}$SRCs are presented in Supplementary Data $3 \mathrm{~b}$ 
all four single CD34- ${ }^{-}$SRC-engrafted mice (CD34- NSG 027, 058, 076 and 079) repopulated each of the two secondary recipient NSG mice (eight mice in total) (Supplementary Data 3a). All eight secondary recipient NSG mice showed distinct multilineage human cell repopulation by 12 to 22 weeks after transplantation (Supplementary Data 3c). The repopulation patterns of one representative NSG mouse $\left(34^{-}\right.$NSG058) are shown in Supplementary Fig. 9a and c. It was quite interesting that the patterns of the multi-lineage repopulation observed in the two secondary recipient mice were not equivalent, suggesting that daughter SRCs generated from the single parental $\mathrm{CD} 34^{+}$and CD $34^{-}$SRCs were functionally heterogeneous.

Finally, we performed tertiary transplantation with whole BM cells from secondarily engrafted recipient mice that originally received single purified $\mathrm{CD} 34^{+}$and CD34- SRCs (Supplementary Data 3a). Two secondary recipient NSG mice $\left(34^{+}\right.$NSG046a and NSG046b) that originally received a single $34^{+} 38^{-} 133^{+} 80^{+}$ cell in primary transplantation engrafted $2 / 4$ tertiary recipient mice 22 weeks after transplantation (Supplementary Fig. 9d). Of note, two secondary recipient NSG mice $\left(34^{-}\right.$NSG058a and NSG058b) that originally received a single $34^{-} 133^{+} 80^{+}$cell in primary transplantation did engraft $4 / 4$ tertiary recipient mice (Supplementary Fig. 9d). All of the tertiary engrafted mice showed multi-lineage human $\mathrm{CD}^{+} 5^{+}$cell repopulation at 22 weeks after transplantation (Supplementary Fig. 9d and Supplementary Data 3d). These results clearly demonstrated that human $\mathrm{CB}$-derived single purified $\mathrm{CD} 34^{+}$and $\mathrm{CD} 34^{-}$SRCs can extensively self-renew in xenografted mice.

$\mathrm{CD}^{-} 4^{-}$HSCs reside at the apex of the human HSC hierarchy. As we reported previously, CD34- 3 RCs (HSCs) are able to generate CD $34^{+}$SRCs (HSCs) in vitro ${ }^{25,35,36}$ and in vivo. ${ }^{18,33}$ In this study, we showed that CD34- SRCs (HSCs) (18 Lin $^{-}$CD34 ${ }^{-} \mathrm{CD} 133^{+} \mathrm{GPI}-80^{+}$cells) were able to generate $\mathrm{CD} 34^{+}$as well as CD34- ${ }^{-}$SRCs (HSCs) in vivo (Supplementary Fig. 7e and f). However, CD $34^{+}$SRCs (HSCs) $\left(18 \mathrm{Lin}^{-} \mathrm{CD} 34^{+} \mathrm{CD} 38^{-} \mathrm{CD} 133\right.$ ${ }^{+} \mathrm{GPI}-80^{+}$cells) were only able to generate CD $34^{+}$SRCs (HSCs) in vivo (Supplementary Figs. $7 \mathrm{~b}$ and $\mathrm{c}$ ). They were unable to generate $\mathrm{CD}^{-} 4^{-}$SRCs (HSCs) in vivo. To elucidate the hierarchical position of the CD34- SRCs (HSCs) (18 $\mathrm{Lin}^{-} \mathrm{CD} 34$ ${ }^{-} \mathrm{CD} 133^{+} \mathrm{GPI}-80^{+}$cells) in comparison to previously wellestablished CD34 ${ }^{+}$SRCs (HSCs) $\left(9 \mathrm{Lin}^{-} \mathrm{CD} 34^{+} \mathrm{CD} 38^{-} \mathrm{CD} 45 \mathrm{RA}\right.$ ${ }^{-} \mathrm{CD}{ }^{+} \mathrm{CD} 4 \mathrm{f}^{+}$cells $)^{3}$, we next co-cultured CB-derived 18Lin ${ }^{-} \mathrm{CD} 34^{-} \mathrm{CD}^{-} 33^{+} \mathrm{GPI}-80^{+}$and $9 \mathrm{Lin}^{-} \mathrm{CD} 34^{+} \mathrm{CD} 38^{-} \mathrm{CD} 45 \mathrm{RA}$ ${ }^{-} \mathrm{CD}{ }^{+}{ }^{\mathrm{CD}} 49 \mathrm{f}^{+}$cells with human BM-derived CD $271^{+} \mathrm{SSEA}-4^{+}$ MSCs (DP MSCs) ${ }^{35}$. The results are shown in Supplementary Fig. 10 and Supplementary Data 4 . The $18 \mathrm{Lin}^{-} \mathrm{CD} 34^{-} \mathrm{CD} 133$ ${ }^{+}$GPI- $80^{+}$cells were able to generate $9 \mathrm{Lin}^{-} \mathrm{CD} 34^{+} \mathrm{CD} 38$ ${ }^{-} \mathrm{CD} 45 \mathrm{RA}^{-} \mathrm{CD}^{-} 0^{+} \mathrm{CD} 49 \mathrm{f}^{+/}-$cells with SRC activities (Supplementary Fig. 10i and j). Furthermore, they were able to generate CD34- SRCs (HSCs) in vitro (Supplementary Fig. 10k). These results are consistent with the findings of the in vivo study, as shown in Supplementary Fig. 7. In contrast, the $9 \mathrm{Lin}^{-} \mathrm{CD} 34$

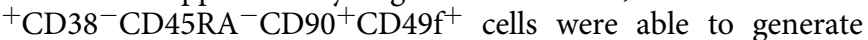
$\mathrm{CD} 4^{+} \mathrm{CD} 38^{-} \mathrm{CD} 4 \mathrm{RA}^{-} \mathrm{CD}^{-}{ }^{+} \mathrm{CD} 49 \mathrm{f}^{+/-}$cells with SRC activities (Supplementary Fig. 10d and e). However, they were unable to generate $\mathrm{CD}^{-} 4^{-} \mathrm{SRCs}$ (HSCs) in vitro (Supplementary Fig. 10f). These results suggest that CD34- SRCs (HSCs) (18Lin ${ }^{-} \mathrm{CD} 34^{-} \mathrm{CD} 133^{+} \mathrm{GPI}-80^{+}$cells) are more immature than $\mathrm{CD} 34^{+}$ SRCs (HSCs) $\left(9 \mathrm{Lin}^{-} \mathrm{CD} 34^{+} \mathrm{CD} 38^{-} \mathrm{CD} 45 \mathrm{RA}^{-} \mathrm{CD}^{-} 0^{+} \mathrm{CD} 49 \mathrm{f}^{+}\right.$ cells) in the human HSC hierarchy, indicating that CD34- ${ }^{-}$SRCs (HSCs) reside at the apex of the human HSC hierarchy.

A unique molecular signature of $\mathrm{CD}^{-} 4^{-}$HSCs. To provide an independent line of evidence for characterizing our highly purified $\mathrm{CD}_{3} 4^{+}$and $\mathrm{CD} 34^{-}$SRCs (HSCs), we analyzed the gene expression profiles of these two classes of SRCs (HSCs) and other types of progenitors and mature cells at the single-cell level. As shown in Fig. 4a, a principal component analysis (PCA) demonstrated that the gene expression profiles of individual CD $34^{-}$HSCs were clearly different from those of $\mathrm{CD}_{3} 4^{+}$and $\mathrm{CD}^{+} 0^{+} \mathrm{HSCs}^{3}$. In contrast, the gene expression profiles of individual $\mathrm{CD}^{+} 4^{+}$and $\mathrm{CD} 90^{+}$HSCs overlapped. An unsupervised hierarchical clustering analysis (Fig. 4b) clearly showed two clusters; 1 and 2 . Interestingly, all CD34- ${ }^{-}$HSCs belonged to cluster 1. Conversely, cluster 2 contained some of CD34 ${ }^{+}$HSCs, $\mathrm{CD}^{+}{ }^{+} \mathrm{HSCs}$ and various HPCs, including multipotent progenitors (MPPs), common myeloid progenitors (CMPs), granulocyte/macrophage progenitors (GMPs), megakaryocyte/ erythrocyte progenitors (MEPs) and multilymphoid progenitors (MLPs). These results demonstrated that the gene expression profiles of $\mathrm{CD}_{3} 4^{-}$HSC were unique and largely different from those of other classes of CD34 ${ }^{+}$HSCs. We then performed a heatmap analysis, as shown in Fig. 4c. We identified three independent clusters that respectively contained HSC/HPC-related (A), HPC-related (B) and mature cell-related (C) genes.

We next focused on the gene expression profiles of primitive $\mathrm{CD}^{+}{ }^{+}$and $\mathrm{CD}^{-} 4^{-}$and CD90 ${ }^{+}$HSCs in the heatmap (Fig. 5a). These three classes of primitive HSCs showed different gene expression profiles. As shown in the upper column of violin plots (Fig. 5b), HSC maintenance genes such as the KIT, RUNX1, TAL1, BMI1, DNMT3A and TGFBR1 and R2 were comparably expressed in these three classes of HSCs. In contrast, genes such as the IFITM1, MPL, IKZF1, ETV6, ALDH1A1 and IGF1R were more highly expressed in $\mathrm{CD}_{3} 4^{+}$and/or CD90 ${ }^{+}$HSCs than in CD34- HSCs (Fig. 5b). Very characteristically, the EZH2 and $M Y B$ genes were turned out to be highly expressed in CD34 ${ }^{-}$HSCs (Fig. 5b). Overall, the PCA and unsupervised hierarchical clustering analyses demonstrated that the gene expression profiles of individual CD34 ${ }^{+}$and CD34- ${ }^{-}$HSCs were clearly different.

Global gene expression analyses of $\mathrm{CD}^{+} 4^{+}$and $\mathrm{CD} 34^{-}$HSCs. Finally, we performed global gene expression analyses of highly purified human $\mathrm{CB}$-derived $18 \mathrm{Lin}^{-} \mathrm{CD} 34^{+} \mathrm{CD} 38^{-} \mathrm{CD} 133^{+} \mathrm{GPI}-$ $80^{+}$cells (referred to as CD34 ${ }^{+}$HSCs) and 18 Lin $^{-}$CD $34^{-} \mathrm{CD} 133$ ${ }^{+} \mathrm{GPI}-80^{+}$cells (referred to as CD34- ${ }^{-}$HSCs). As a control, we sorted $18 \mathrm{Lin}^{-} \mathrm{CD} 34^{+} \mathrm{CD} 133^{-}$cells (referred to as non-SRCs [non-HSCs]), that had an undetectable level of SRC activity, as previously reported ${ }^{22}$.

First, we compared the gene expression profiles of $\mathrm{CD}_{3}{ }^{+}$and CD34- ${ }^{-}$HSCs using a gene set enrichment analysis (GSEA). Gene sets enriched in $\mathrm{CD} 34^{+}$HSCs are those related to interferon $\alpha / \beta /$ $\gamma$ response/signaling, cell adhesion/migration, cytokine signaling in the immune and inflammatory responses (Fig. 6a right). Gene sets enriched in $\mathrm{CD}_{3}{ }^{-}$HSCs are those related to hypoxia, ontogeny, megakaryocyte/erythrocyte differentiation, Wnt signaling and angiogenesis (Fig. 6a left). As described above, the CD34 HSCs showed potent megakaryocyte/erythrocyte differentiation potential in vitro and in vivo. It is interesting that the gene set related to megakaryocyte/erythrocyte differentiation was enriched in CD34- HSCs.

We then focused on the signaling pathways important for the HSC function and maintenance. Interestingly, CD34 ${ }^{-}$HSCs expressed higher levels of the gene set related to Wnt signaling (Fig. 6a, b), while CD34 ${ }^{+}$HSCs expressed higher level of the gene sets related to IFN- $\alpha$, IFN- $\gamma$, TGF- $\beta$ and Notch signaling (Fig. $6 a$, c). As mentioned above, a single-cell gene expression analysis clearly showed that $\mathrm{CD} 34^{-}$HSCs expressed lower levels of IFITM1 than CD34 ${ }^{+}$HSCs (Fig. 5b). Therefore, we next analyzed the IFN-related signaling genes. As shown in Supplementary 
a

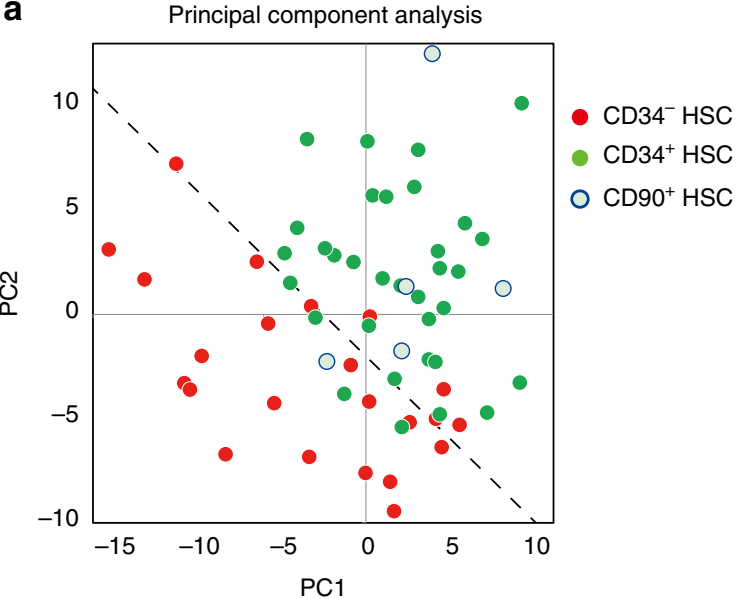

b

Hierarchical clustering analysis: dendrogram

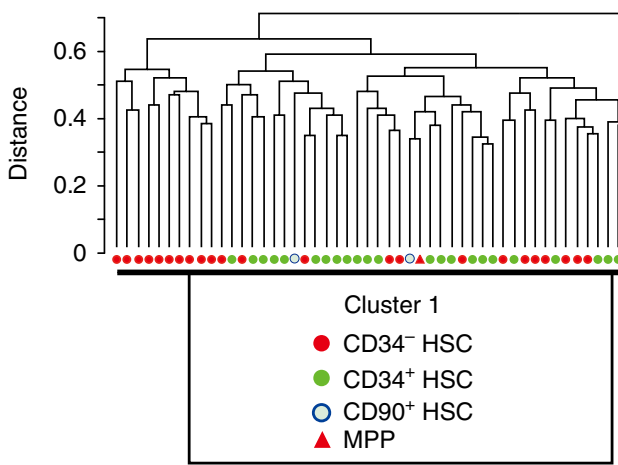

Stem cell cluster

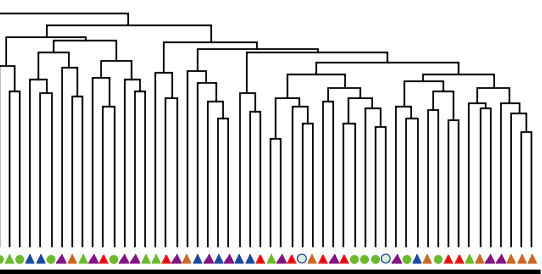

Cluster 2

- $\mathrm{CD}_{3} 4^{+} \mathrm{HSC}$

O $\mathrm{CD}^{\circ} 0^{+} \mathrm{HSC}$

$\triangle$ MPP

$\triangle \mathrm{CMP}$

$\triangle$ GMP

$\triangle \mathrm{MEP}$

$\triangle \mathrm{MLP}$

C

Progenitor cluster

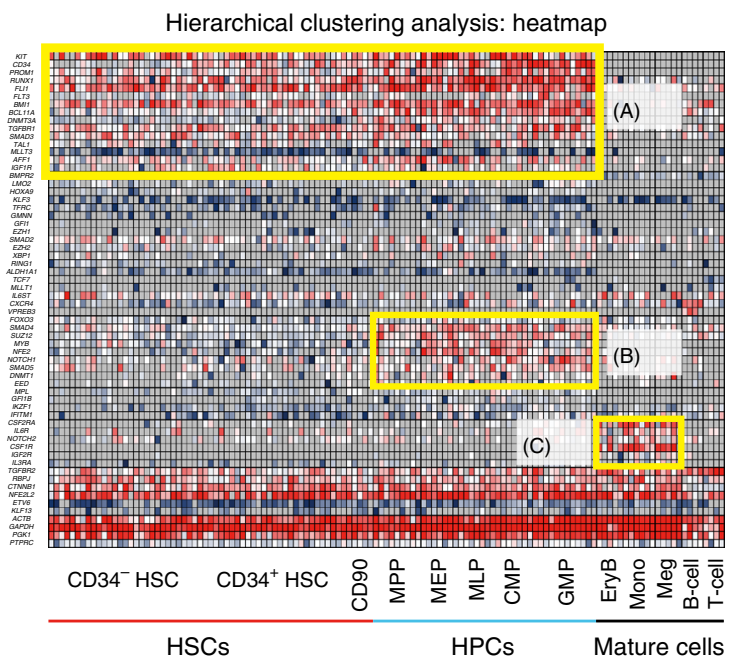
HSC/HPC HPC

Mature cell | Ubiquitously expressed |Reference

\section{HSCs}

HPCs

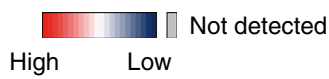

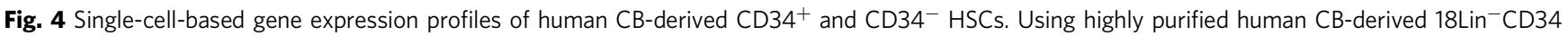
${ }^{+} \mathrm{CD}_{3}{ }^{-} \mathrm{CD} 133^{+} \mathrm{GPI}-80^{+}$and $18 \mathrm{Lin}^{-} \mathrm{CD}^{-}{ }^{-} \mathrm{CD} 133^{+} \mathrm{GPI}-80^{+}$cells, we performed a single-cell-based gene expression analysis. The immunophenotypes of target cells, including controls, are presented in Supplementary Data 6 and the 79 target genes that play important roles in the pathway of HSC development/ differentiation ${ }^{63}$ are listed in Supplementary Data 7. a A principal component analysis (PCA) revealed that the gene expression profiles in individual CD34 ${ }^{+}$ $(n=33)$ and $\mathrm{CD}_{4} 4^{-} \mathrm{HSCs}(n=23)$ were clearly different. The gene expression profiles of individual $\mathrm{CD}_{90}{ }^{+} \mathrm{HSCs}(n=5)$ were similar to those of $\mathrm{CD} 34^{+}$ HSCs but not to those of CD34-HSCs. The dotted line represents the border region between the $\mathrm{CD}_{3} 4^{+}$and $\mathrm{CD} 34^{-}$HSCs calculated by a Fisher's linear discriminant analysis. b An unsupervised hierarchical clustering analysis (Dendrogram) clearly showed two clusters, 1 and 2. Interestingly, all CD34-HSCs belong to cluster 1. Three subgroups were detected in cluster 1. The left-most subgroup uniformly contained 10 CD34- HSCs. The remaining 13 CD34- HSCs were scattered between the other two subgroups mixed with $\mathrm{CD} 34^{+} \mathrm{HSCs}$ and $\mathrm{CD} 90^{+} \mathrm{HSCs}$ and MPPs. In contrast, some of the $\mathrm{CD} 34^{+} \mathrm{HSCs}$ and $\mathrm{CD} 90^{+}$ $\mathrm{HSCs}$, most of the MPP, and all other HPCs (CMP, GMP, MEP and MLP) belonged to cluster 2. These results demonstrated that the gene expression profiles of CD34- HSC were unique and largely differed from those of other classes of CD34+ HSPCs. c A hierarchical clustering analysis of 62 genes (heatmap) detected 3 clusters (a-c), which are highlighted with yellow squares. Cluster (A) contained HSC/HPC-related genes, including RUNX1, BMI1, DNMT3a and SCL/TAL1, in addition to CD34 and PROM1 (CD133). Cluster (B) contained HPC-related genes, including MYB, FOXO3A, SMAD4, NFE2 and NOTCH1. Cluster (C) contained mature cell-related genes, including those for various cytokine receptors (CSF2RA, IL-6R, CSF1R, IGF2R and IL-3RA) 
Fig. 11, CD34 ${ }^{+}$and CD34- ${ }^{-}$HSCs expressed comparable levels of IFNAR1 and R2 receptors, TYK2 and JAK1. However, CD34HSCs expressed significantly lower levels of their downstream target genes, including STAT1, IFITM1, IFITM3, DDX58, IFI44, CXCL10 and CXCL11 than CD34 ${ }^{+}$HSCs. As recently reported, high levels of IFN- $\alpha$ activated dormant HSCs in vivo ${ }^{37,38}$. These results therefore suggest that $\mathrm{CD} 34^{-}$HSCs may be more resistant than $\mathrm{CD}_{3} 4^{+}$HSCs to chronic activation of the IFN-a pathway.
Next, we compared the gene expression profiles of $\mathrm{CD}_{3}{ }^{+}$and CD34- SRCs (HSCs) with those of non-SRCs (non-HSCs) by a GSEA. The results showed that gene sets related to quiescence, inflammatory signaling, HSC markers, cell adhesion, cytokine signaling and chemokine/migration were enriched in $\mathrm{CD}_{3}{ }^{+}$and CD34- ${ }^{-}$RCs (HSCs) (Supplementary Fig. 12a right). In contrast, gene sets related to cell cycle progression, differentiation, DNA replication, metabolism and organellar activity were enriched in

a Gene expression profiles of $\mathrm{CD} 34^{-}, \mathrm{CD} 34^{+}$and $\mathrm{CD} 90^{+} \mathrm{HSCs}$ (heatmap) Gene symbol

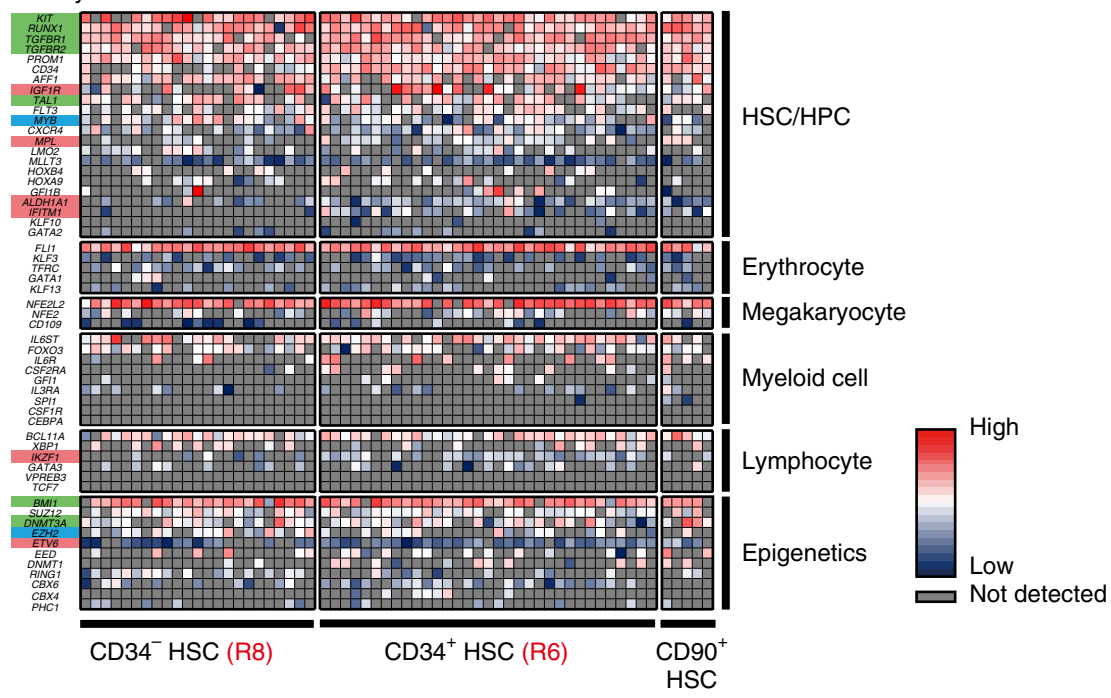

b Gene expression profiles of $\mathrm{CD} 4^{-}, \mathrm{CD} 34^{+}$and $\mathrm{CD} 90^{+} \mathrm{HSCs}$ (violin plots)

HSC maintenance genes highly expressed in $\mathrm{CD} 34^{-}, \mathrm{CD} 34^{+}$and $\mathrm{CD}^{+} 0^{+} \mathrm{HSCs}$ (highlighted by green)

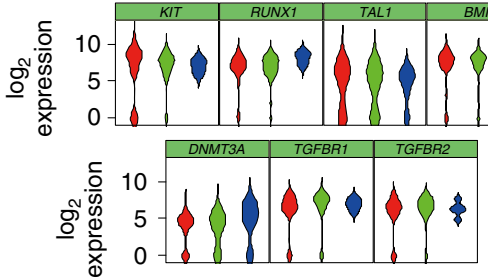

Genes highly expressed in $\mathrm{CD} 34^{+} \mathrm{HSCs}$ compared with CD34 ${ }^{-}$HSCs (highlighted by pink)

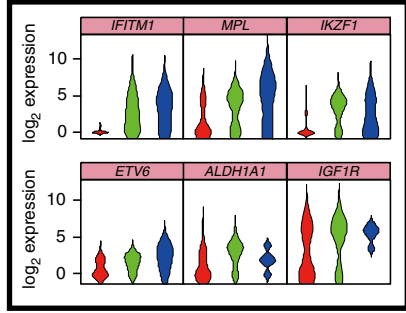

Genes highly expressed in $\mathrm{CD} 34^{-} \mathrm{HSCs}$ compared with $\mathrm{CD} 34^{+}$HSCs (highlighted by blue)

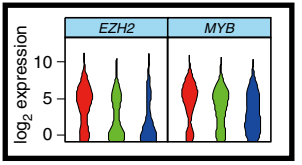

C Expression of reference genes and genes for CD34, CD133 and GPI-80

Reference genes

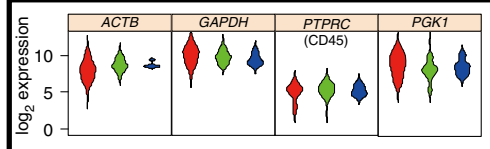

CD34 and CD133

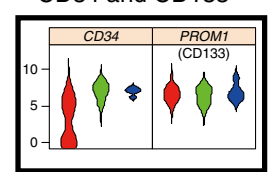

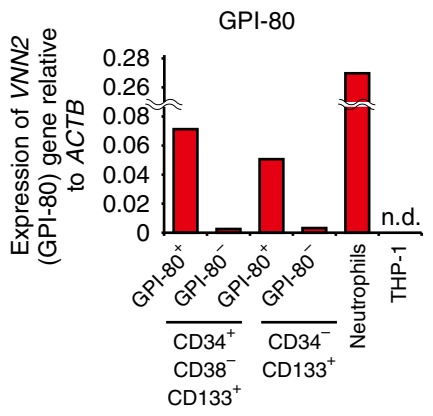


non-SRCs (non-HSCs) (Supplementary Fig. 12a left). We then selected the 1323 differentially expressed probes with a >twofold difference in expression between $\mathrm{CD}_{3}{ }^{+}$and CD34 ${ }^{-}$SRCs and non-SRCs (Supplementary Fig. 12b). A heatmap analysis identified several marker molecules previously reported for characterizing/purifying human HSCs, including ITGA6, PROCR, endothelial cell-selected adhesion molecule (ESAM) and PROM1 (CD133). $\mathrm{CD}^{+} 4^{+}$and CD34- ${ }^{-}$SRCs (HSCs) expressed higher levels of ITGA6 (CD49f) than non-SRCs, which was consistent with a recent report that CD49f was a specific HSC marker for human $\mathrm{CB}$-derived $\mathrm{CD}^{+}{ }^{+} \mathrm{HSCs}^{3}$. Interestingly, $\mathrm{CD}_{3} 4^{+}$and CD34- ${ }^{-}$RCs (HSCs) expressed higher levels of PROCR (EPCR) than non-SRCs. As recently reported ${ }^{39}$, EPCR/PAR1 signaling facilitated LT-HSC BM repopulation, retention and the survival. Very recently, Yokota et al. reported that ESAM was a useful purification marker for human $\mathrm{BM}$ and $\mathrm{CB}$-derived $\mathrm{HSCs}^{40}$. As expected from our ultra-high-resolution purification method, $\mathrm{CD}^{+}{ }^{+}$and $\mathrm{CD}^{-} 4^{-}$SRCs (HSCs) expressed higher levels of PROM1 (CD133) than non-SRCs. In contrast, non-SRCs expressed higher levels of the CD93 gene, which was reported to be a positive marker for human CB-derived CD34- ${ }^{-} \mathrm{HSCs}^{41}$. However, as shown in Supplementary Fig. 1, our highly purified $34^{-} 133^{+} 80^{+}$cells did not express CD93 at all. Collectively, these GSEAs demonstrated a clear difference between these two classes of $\mathrm{CD}_{4} 4^{+}$and $\mathrm{CD}_{3} 4^{-}$SRCs (HSCs), suggesting that CD34 HSCs are a distinct class of human primitive HSCs in comparison to $\mathrm{CD} 34^{+}$HSCs.

Ex vivo expansion of CD34- ${ }^{-}$HSCs. Thus far, approximately 40,000 CB transplantations (CBTs) have been performed worldwide for children and adults with severe hematological diseases. ${ }^{42-44}$ Thus, CB is now one of the most commonly used sources for allogeneic hematopoietic stem cell transplantation (HSCT). ${ }^{42-44}$ However, the number of HSCs residing in CB units is limited resulting in delayed neutrophil and platelet recovery and engraftment failure. Both are life-threatening complications. To overcome these clinical challenges, efficient ex vivo expansion of CB-derived HSCs is awaited.

The purine derivative StemRegenin-1 (SR-1) was first identified to promote the expansion of $\mathrm{CD} 34^{+}$HSCs/HPCs. ${ }^{45}$ Cultures of $\mathrm{CB}$-derived $\mathrm{CD}_{3} 4^{+}$cells in the presence of SCF $+\mathrm{TPO}+\mathrm{FL}+$ SR-1 led to a 50-fold increase in $\mathrm{CD}^{+}{ }^{+}$cells and a 17 -fold increase in SRCs. Recently, a pyrimidoindole derivative (UM171) was found to attenuate cell differentiation and promoted the ex vivo expansion of $\mathrm{CB}$-derived $\mathrm{CD} 34^{+} \mathrm{CD} 45 \mathrm{RA}^{-}$cells. ${ }^{46}$ Interestingly, the frequencies of LT-HSCs were 13-fold higher in cultures supplemented with UM171 than in those supplemented with DMSO control. Given these findings, we tried to expand very primitive CB-derived CD34- ${ }^{-}$SRCs (HSCs) (18Lin ${ }^{-} \mathrm{CD} 34^{-} \mathrm{CD} 133^{+} \mathrm{GPI}-80^{+}$cells) using $\mathrm{SCF}+\mathrm{TPO}+\mathrm{FL}+\mathrm{SR}-1$ or UM171. As shown in Supplementary Fig. 13c and d, 18Lin ${ }^{-} \mathrm{CD} 34^{-} \mathrm{CD} 133^{+} \mathrm{GPI}-80^{+}$cells actively proliferated and showed 460 -fold (UM171) to 950-fold (SR-1) increases in total numbers of cells, yielding $9 \times 10^{5}$ (UM171) to $13 \times 10^{5}$ (SR-1) 12Lin ${ }^{-} \mathrm{CD} 45 \mathrm{RA}^{-} \mathrm{CD} 34^{+}$cells. We then performed LDAs to analyze their effects on the expansion of SRCs (Supplementary Fig. 13e and f). Unfortunately, we were unable to expand CD34- ${ }^{-}$SRCs (HSCs). As shown in this study (Supplementary Figs. 7 and 10), CD $34^{-}$SRCs (HSCs) did generate CD $34^{+}$SRCs (HSCs) in these cultures in the presence of cytokines plus SR-1 or UM171 (Supplementary Fig. 13a and b). However, the expansion efficiencies were 1.33 for SR-1 and 0.42 for UM171 (Supplementary Fig. 13a and f). These efficiencies were not statistically significant in comparison to DMSO (control). These results showed that the ex vivo expansion of primitive CB-derived CD34 - SRCs (HSCs) was more difficult than previously considered, and suggesting that ex vivo expansion of primitive $\mathrm{CB}$-derived CD34- ${ }^{-}$SRCs (HSCs) may require niche cells/factors for maintenance and/or proliferation. Further studies will be needed to clarify the details of this important issue.

\section{Discussion}

We developed an ultra-high-resolution purification method using two positive markers, CD133 and GPI-80, and succeeded in highly purifying human $\mathrm{CB}$-derived $\mathrm{CD} 34^{+}$and $\mathrm{CD} 34^{-}$SRCs (HSCs) at $1 / 5$ and $1 / 8$ cell levels, respectively. GPI- 80 has recently been reported as a positive marker for human fetal liver hematopoietic stem/progenitor cells (HSPCs) ${ }^{47}$. Because human placenta/CB-derived HSPCs reflect fetal hematopoiesis ${ }^{30,31}$, it is conceivable that GPI-80 is expressed on CB-derived primitive HSCs. Interestingly, both CD133 and GPI-80 were correlated with the polarization and migration of leukocytes and HSPCs ${ }^{23,24,48,49}$. Thus, these two molecules seem to be functional markers. Our updated method enables us to perform single-cellbased transplantation analyses. Both groups of engrafted mice that received single $34^{+} 38^{-} 133^{+} 80^{+}$or $34^{-} 133^{+} 80^{+}$cells showed distinct secondary repopulation capability with multilineage differentiation. It is noteworthy that $1 / 6$ and $4 / 6$ primarily engrafted NSG mice that received single $34^{+} 38^{-} 133^{+} 80^{+}$and 34 ${ }^{-} 133^{+} 80^{+}$cells robustly repopulated two secondary recipient mice, respectively (Supplementary Data 3a and Supplementary Fig. 9a to c). Furthermore, both $\mathrm{CD} 4^{+}$and $\mathrm{CD} 34^{-}$SRCs showed substantial single-cell-initiated tertiary repopulating capacities (Supplementary Data 3a and Supplementary Fig. 9d). This indicates that both SRCs sustained human multi-lineage hematopoiesis in NSG mice for over one year (Supplementary Data 3a). These results showed that individual $\mathrm{CD}^{+} 4^{+}$and $\mathrm{CD} 34^{-}$SRCs (HSCs) have potent proliferative and extensively self-renewing capacities.

In this study, the single-cell transplantation efficiencies of highly purified $34^{+} 38^{-} 133^{+} 80^{+}$and $34^{-} 133^{+} 80^{+}$cells were 11 and $6 \%$, respectively (Supplementary Data $3 a$ ), which were still relatively low. The xenotransplantation assay with NOG/NSG mice for detecting SRC activity, however, is not an ideal assay system, partly because of its species specificity ${ }^{50}$. As we showed in the present study, single $\mathrm{CD} 34^{+}$and $\mathrm{CD} 34^{-}$SRCs exerted robust

Fig. 5 A comparison of the gene expression profiles of single-purified human CB-derived CD34 ${ }^{+}$and $\mathrm{CD}_{3} 4^{-}$and $\mathrm{CD} 90^{+} \mathrm{HSCs}_{\text {by }}$ qRT-PCR. Multi-plex (79 genes) single-cell qRT-PCR using $\mathrm{CD}_{3} 4^{+}$and $\mathrm{CD} 34^{-} \mathrm{HSC}$ and $\mathrm{CD} 90^{+} \mathrm{HSC}$ s was performed. a The 54 gene expression profiles in $\mathrm{CD} 34^{+}$and $\mathrm{CD} 34$ ${ }^{-} \mathrm{HSCs}$ and $\mathrm{CD} \mathrm{O}^{+} \mathrm{HSC}$ are depicted using a heatmap. These 54 genes were classified as HSC/HPC-, erythrocyte-, megakaryocyte-, myeloid cell-, lymphocyte- and epigenetics-related genes. $\mathbf{b}$ The expression of individual genes in CD34+ and CD34- HSCs and CD90 ${ }^{+} \mathrm{HSCs}$ is depicted by violin plots. The HSC maintenance genes highly expressed in both $\mathrm{CD}_{3} 4^{+}$and CD34- $\mathrm{HSCs}$ and CD90 ${ }^{+} \mathrm{HSCs}$ (KIT, RUNK1, TAL1, BMI1, DNMT3A, TGFBR1 and R2) are shown in the upper panel and highlighted by green color in a. The genes highly expressed in CD34 ${ }^{+}$HSCs (IFITM1, MPL, IKZF1, ETV6, ALDH1A1 and IGF1R) are shown in the middle left panel and highlighted by pink color in $\mathbf{a}$. The genes highly expressed in CD34- HSCs (EZH2 and MYB) are shown in the middle right panel and highlighted by blue color in a. The gate names (R6 and R8) presented in this figure correspond to the same fractions in Fig. 1e, f. c Violin plots of the reference genes, including ACTB, GAPDH, PTPRC (CD45) and PGK-1 (left). Violin plots of the genes for CD34 and PROM1 (CD133) (middle). qRT-PCR of the VNN2 (GPI-80) mRNA expression in the $18 \mathrm{Lin}^{-} \mathrm{CD} 34^{+} \mathrm{CD} 38^{-} \mathrm{CD} 133^{+} \mathrm{GPI}-80^{+/}-$and $18 \mathrm{Lin}^{-} \mathrm{CD} 34^{-} \mathrm{CD} 133^{+} \mathrm{GPI}_{-} 80^{+/}-\mathrm{cells}^{-}$compared with the positive control (CB-derived neutrophils) and negative control (THP-1 cells) (right). n.d.: not detected 
a

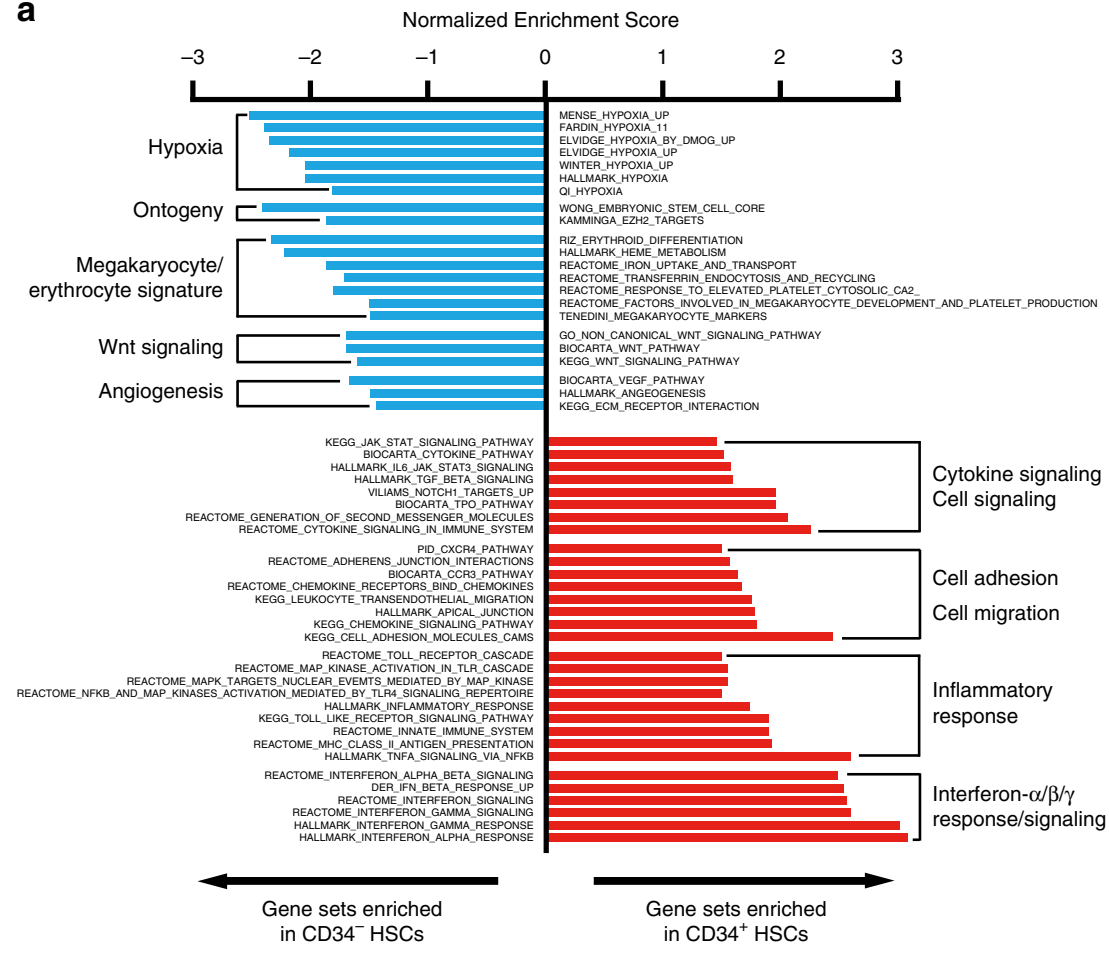

b

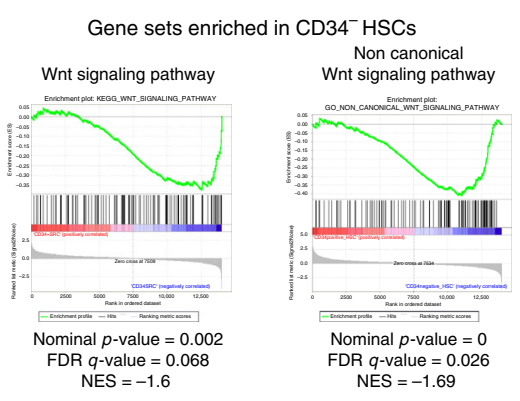

C

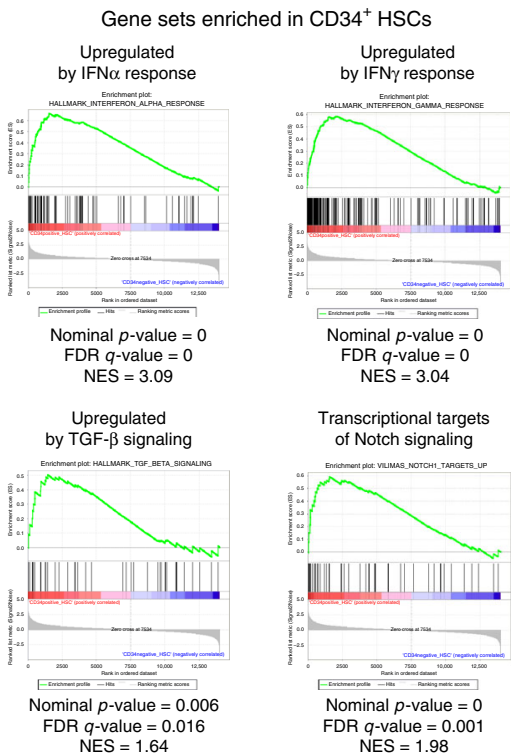

Fig. 6 A comparison of the gene expression profiles between $\mathrm{CD}_{3} 4^{+}$and $\mathrm{CD} 34^{-}$SRCs (HSCs) by a microarray. a The gene expression profiles of CD34 ${ }^{+}$ and CD34- SRCs (HSCs) were compared by a Gene Set Enrichment Analysis (GSEA) using the data from the microarray analysis. The gene sets enriched in CD34- SRCs (blue bar) and those in CD34+ SRCs (red bar) with a Normalized Enrichment Score $<-1$ or $>1$ were selected and presented. Detailed lists of the genes in each gene set depicted in the figure can be found in the GSEA Molecular Signatures Database (http://software.broadinstitute.org/gsea/ msigdb/index. jsp). b, c The gene expression profiles that related to the signaling pathways for the HSC maintenance were precisely analyzed. $\mathbf{b}$ Enrichment plot of the gene sets (presented in a) which were enriched in $\mathrm{CD}_{3} 4^{-} \mathrm{HSCs}$ and $\mathbf{c}$ in $\mathrm{CD}_{3} 4^{+} \mathrm{HSCs}$ are depicted

engraftment potentials without any accessory cells in recipient NOG/NSG mice, indicating that unidentified mouse niche cells/ factors can support human HSCs, at least in the initial phase of xenotransplantation, across the species barrier. This is an important issue that should be addressed in the future in order to improve the efficiency of single-cell transplantation and to further clarify the HSC-supporting mechanism.

Single-cell-based gene expression analyses, such as the PCA analysis and unsupervised hierarchical clustering analysis, demonstrated that gene expression profiles of individual $\mathrm{CD} 34^{+}$and CD $34^{-}$HSCs were clearly different (Fig. $4 \mathrm{a}, \mathrm{b}$ ). However, immunophenotypically homogeneous $\mathrm{CD} 34^{-} \quad\left(18 \mathrm{Lin}^{-} \mathrm{CD} 34^{-}\right.$ $\left.\mathrm{CD} 133^{+} \mathrm{GPI}-80^{+}\right)$and $\mathrm{CD}^{+} 4^{+} \quad\left(18 \mathrm{Lin}^{-} \mathrm{CD} 34^{+} \mathrm{CD} 38^{-}\right.$ $\mathrm{CD} 133^{+} \mathrm{GPI}-80^{+}$) HSCs are still very heterogeneous from the point of gene expression. These findings may reflect the variable hematopoietic repopulation patterns of individual $\mathrm{CD}_{3}{ }^{-}$and CD34 ${ }^{+}$SRCs (HSCs) observed in the BM, PB and spleen (Supplementary Data 3a to c). As shown in Fig. 5b, individual CD34HSCs showed unique gene expression profiles, including for the IFITM1, MPL, IKZF1, ETV6, ALDH1A1, IGF1R, EZH2 and MYB genes, in comparison to $\mathrm{CD} 34^{+}$HSCs. Furthermore, GSEAs also demonstrated clear differences between these two classes of $\mathrm{CD}^{2}{ }^{+}$and $\mathrm{CD} 34^{-} \mathrm{HSCs}$ (Fig. 6). Among them, we focused on the expression of IFITM1. The expression of IFITM1 in individual CD34- HSCs was extremely low in comparison to CD34 ${ }^{+}$
HSCs (Fig. 5b). In addition, the GSEA demonstrated that gene sets related to IFN- $\alpha / \beta / \gamma$ response/signaling are enriched in $\mathrm{CD} 34^{+}$HSCs. As expected, genes related to IFN signaling, including STAT1, IFITM1, IFITM3, DDX58, IFI44, CXCL10 and CXCL11, showed significantly higher expression in CD $34^{+}$HSCs than in CD34- HSCs (Supplementary Fig. 11). It is welldocumented that type I IFNs are essential for establishing the host antiviral state. However, their roles in human steady-state hematopoiesis have not been elucidated. Our present data suggest that CD34- ${ }^{-}$HSCs may be more resistant than CD $34^{+}$HSCs to chronic activation of the IFN- $\alpha$ pathway. This suggests that CD34- HSCs may be able to keep their dormancy and survive under the emerging condition. Taken together, these results suggest that independent molecular backgrounds control selfrenewal, maintenance and epigenetic regulation in these two classes of $\mathrm{CD} 34^{+}$and $\mathrm{CD} 34^{-}$HSCs. The application of the current ultra-high-resolution purification method may provide a clue for uncovering fundamental molecular mechanisms that control human CB-derived CD $34^{+}$and $\mathrm{CD} 34^{-}$HSCs.

Over the past two decades, the road map of murine HSC differentiation has been reevaluated due to the accumulation of new findings in this field ${ }^{51-53}$. However, that of humans has remained relatively unchanged. Under the current model $^{1}$ (Fig. 7a), the immunophenotype of LT-HSC is $\mathrm{Lin}^{-} \mathrm{CD} 34^{+} \mathrm{CD} 38^{-} \mathrm{CD} 45 \mathrm{RA}$ ${ }^{-} \mathrm{CD} 90^{+} \mathrm{CD} 49 \mathrm{f}^{+3}$. These LT-HSCs give rise to MPPs, MLPs, 
a

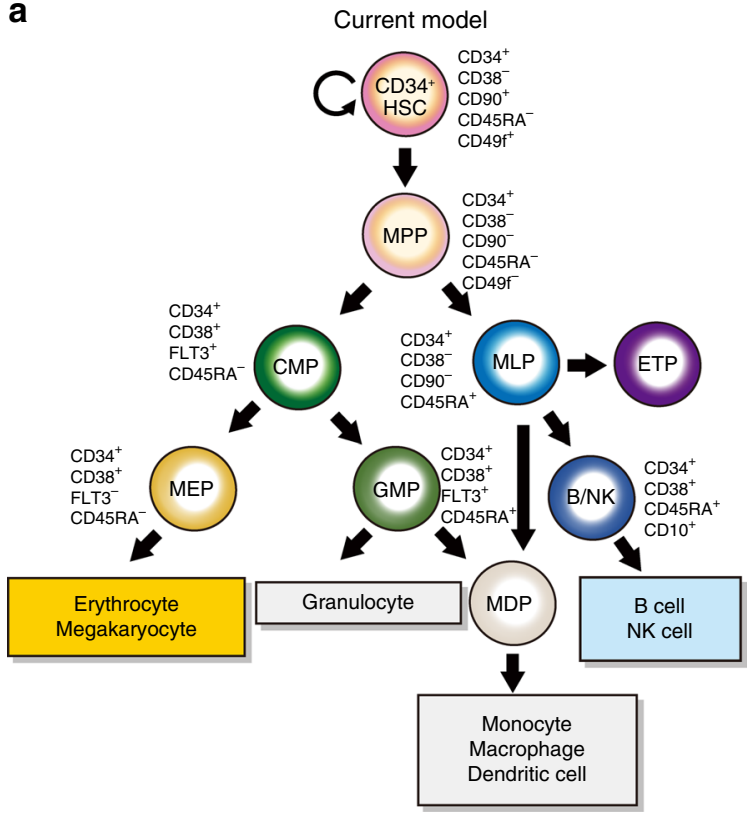

b

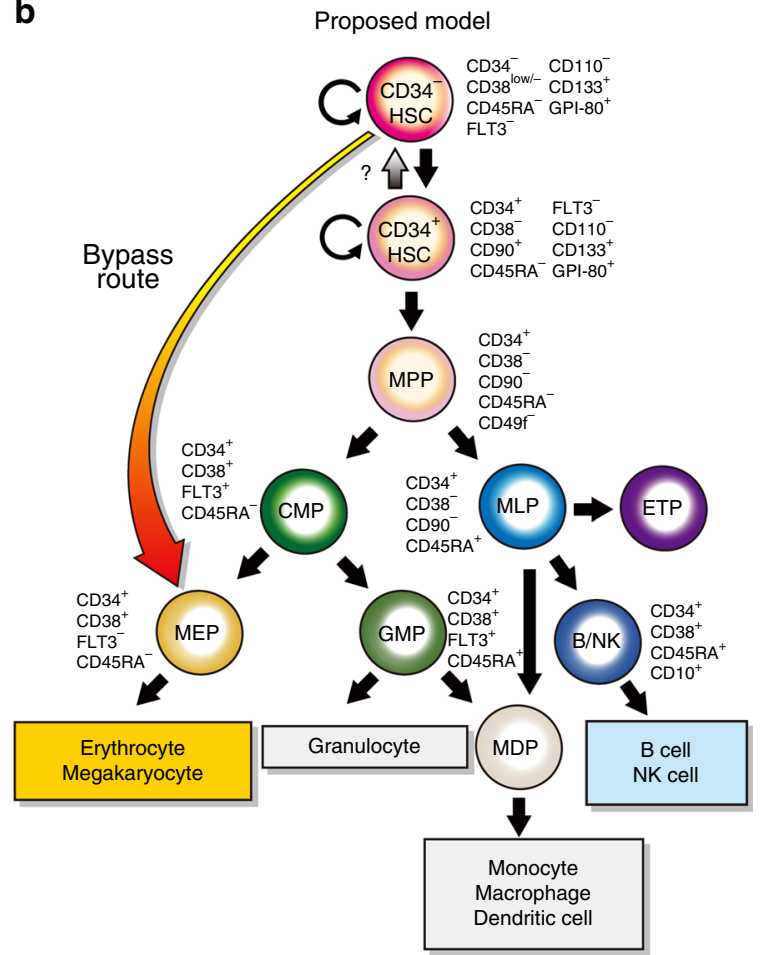

Fig. 7 The current and proposed models for human HSC hierarchy. a The current model ${ }^{1-3}$ for the human HSC hierarchy. CD34 ${ }^{+} \mathrm{HSCs}$ as defined by a

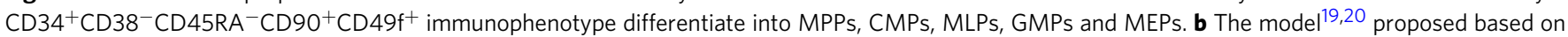

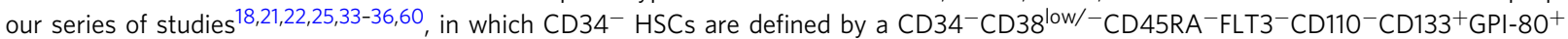

immunophenotype. CD34- $4^{-}$SCs generate $\mathrm{CD}^{+} 4^{+} \mathrm{HSCs}$ in vitro $25,35,36$ and in vivo ${ }^{18,33}$, suggesting that $\mathrm{CD}^{-} 4^{-}$HSCs reside at the apex of human $\mathrm{HSC}^{-}$ hierarchy. CD34 ${ }^{-}$HSCs, then, differentiate into MPPs, CMPs, GMPs and MEPs according to the current model ${ }^{1-3}$. Incorporating the present studies, a revised road map, which allows a commitment/differentiation pathway of CD34- HSCs directly into MEPs (bypass route), is shown. MPP: multipotent progenitor, MLP: multilymphoid progenitor, CMP: common myeloid progenitor, GMP: granulocyte/macrophage progenitor, MEP: megakaryocyte/ erythrocyte progenitor

CMPs, GMPs and MEPs ${ }^{1-3}$ which are basically close to the mouse model. The findings concerning HSC biology obtained in mice cannot, however, always be extrapolated to humans. Therefore, it is necessary to perform validation studies using human HSCs. Doulatov et al. reported a revised road map for the human HPC hierarchy ${ }^{2}$. They showed that monocytes/macrophages and dendritic cells arise in early lymphoid specification. As very recently reported by Notta et al., human fetal liver contained oligopotent progenitors, while few oligopotent progenitors were present in adult BM that was proposed by the precise analysis of single purified $\mathrm{CD}_{3}{ }^{+} \mathrm{HSCs}^{54}$.

In the present study, we analyzed the lineage potentials of highly purified human $\mathrm{CB}$-derived $\mathrm{CD} 34^{+}$and $\mathrm{CD} 34^{-} \mathrm{HSCs}$ in vitro as well as in vivo. Single-purified CD34 ${ }^{+}$HSCs mainly formed CFU-Mix colonies in addition to CFU-GM and BFU-E. In contrast, single-purified CD34- HSCs mainly formed CFUEM colonies. Unexpectedly, $90 \%$ of the colonies formed by 34 ${ }^{-} 133^{+} 80^{-}$cells were CFU-EM (Fig. 1j). When we transplanted CD34- HSCs into NOG/NSG mice, they were able to produce CD34 ${ }^{+}$HSCs in vivo, as previously reported ${ }^{18,33}$ and gave rise to all types of hematopoietic cells (Figs. 2 and 3 ). When we cocultured CD $34^{-}$HSCs with DP MSCs ${ }^{35}$ in the presence of a cocktail of cytokines, they produced $\mathrm{CD}_{3}{ }^{+}$HSCs in vitro (Supplementary Fig. 10 and Supplementary Data 4) as previously reported $^{25,35,36}$. After co-culturing, the recovered cells were recultured in methylcellulose to confirm their lineage potentials, and all types of CFCs, including CFU-GM, BFU-E and CFU-Mix, were detected ${ }^{35}$. These results suggest that CD34-HSCs can generate $\mathrm{CD}_{3}{ }^{+}$HSCs in the presence of DP MSCs (niche cells) and give rise to all types of hematopoietic progenitor cells, as observed in xenotransplantation (Supplementary Fig. 7). As shown in Supplementary Fig. 14, the violin plot and heatmap revealed that the gene expression profiles of $\mathrm{CD} 34^{+}$and $\mathrm{CD} 34^{-}$ HSCs and MEPs were clearly different. The MEPs expressed higher levels of the NFE2, GFI1B, GATA2, TFRC, MYC and MYB genes than $\mathrm{CD}_{3} 4^{+}$and CD34- ${ }^{-}$HSCs. Interestingly, CD34- ${ }^{-} \mathrm{HSCs}$ expressed higher levels of the $M Y B$ gene, which regulates the biphenotypic fate of human $\mathrm{MEPs}^{55}$, than CD $34^{+}$HSCs. It is true that the gene expression profiling solely is not sufficient to argue for the molecular implication in the difference in self-renewal, maintenance and epigenetic regulation of our currently identified HSC subpopulations. We, however, believe that the difference in the gene expression profiling between the HSC subpopulations provides an important clue for elucidating the molecular background sustaining the differential cellular functions of these HSC subpopulations.

Collectively, in vivo, CD34- HSCs can differentiate in line with our proposed model (Fig. 7b). They first generate CD34 ${ }^{+}$HSCs, which then give rise to MPPs, MLPs, CMPs, GMPs and MEPs. In contrast, in methylcellulose cultures, CD34- HSCs may bypass the stage of $\mathrm{CD} 34^{+}$HSCs and directly differentiate into MEPs. Consistent with this hypothesis, CD $34^{-}$HSCs expressed a higher level of gene sets related to megakaryocyte/erythrocyte differentiation (Fig. 6a) and displayed stronger megakaryocyte/erythrocyte differentiation capability even in vivo (Supplementary Fig. 8a). Based on the present studies, we propose a revised megakaryocyte/erythrocyte bypass route as shown in Fig. $7 \mathrm{~b}$. However, it remains as a possibility that CD34- ${ }^{-}$HSCs are able to 
differentiate via $\mathrm{CD} 34^{+}$HSCs in line with our proposed model under influence of the specific niche cells/factors as seen in vivo.

As shown in Supplementary Fig. 15, we did not detect 18 $\mathrm{Lin}^{-}$ $\mathrm{CD} 34^{-} \mathrm{CD} 133^{+} \mathrm{GPI}-80^{+}$cells in adult $\mathrm{BM}$ cells. These results suggest that $\mathrm{CD} 34^{-}$HSCs may be a $\mathrm{CB}$-specific population, while there is a possibility that young adults' or childrens' BMs contain CD $34^{-}$HSCs.

In conclusion, our present study has major implications for the precise characterization of the most primitive class of human CD34- HSCs as well as for HSCT in transplantation medicine. From the viewpoint of HSCT, it is important to develop an efficient method for expanding CB-derived HSCs for transplantation, as $\mathrm{CB}$ transplantation (CBT) is now one of the most commonly used sources for allogeneic HSCT worldwide ${ }^{42-44}$. However, the number of HSCs in CB units is limited, so CBT is often associated with delayed neutrophil and platelet recovery as well as graft failure, which represents a life-threatening complication $^{42-44}$. In this study, we tried to expand very primitive $\mathrm{CB}$ derived CD $34^{-}$SRCs (HSCs) $\left(18\right.$ Lin $^{-} \mathrm{CD} 34^{-} \mathrm{CD} 133^{+}$GPI- $80^{+}$ cells) using SCF, TPO, FL plus StemRegenin-1 (SR-1) ${ }^{45}$ or pyrimidoindole derivative (UM171) ${ }^{46}$. However, it was hard to expand $\mathrm{CD} 34^{-}$and $\mathrm{CD} 34^{+}$SRCs (HSCs) under these culture conditions (Supplementary Fig. 13). Further studies will be required to develop an efficient method for HSC ex vivo expansion.

\section{Methods}

Collection of CB and bone marrow samples. $\mathrm{CB}$ samples were obtained from normal full-term deliveries with written informed consent. Human BM samples were obtained from healthy donor BM remaining in the collection bag after clinical BM transplantation with informed consent. This study was approved by the Institutional Review Board of Kansai Medical University. The CB- and BM-derived lineage-negative $\left(\mathrm{Lin}^{-}\right)$mononuclear cells were separated using an EasySep Human Progenitor Cell Enrichment Kit (StemCell Technologies, Vancouver, BC, Canada) in accordance with the manufacturer's instructions, as previously reported $^{18,21,22,25,33-36}$

Immunostaining of Lin $^{-}$cells for flow cytometry and sorting. The pooled abovementioned CB-derived Lin ${ }^{-}$cells from multiple donors were stained with various monoclonal antibodies (mAbs) (Supplementary Data 5) for $30 \mathrm{~min}$ at $4{ }^{\circ} \mathrm{C}$ in $\mathrm{Ca}^{2+}$ - and $\mathrm{Mg}^{2+}$-free phosphate-buffered saline (PBS ${ }^{-}$) (Nacalai Tesque, Kyoto, Japan) containing $2 \%$ fetal calf serum (FCS) (Biofill, Elsternwick Victoria, Australia) $\left(\mathrm{PBS}^{-} / \mathrm{FCS}\right)$. We used fluorescein isothiocyanate (FITC)-conjugated $18 \mathrm{Lin}$ mAbs, against CD2, CD16, CD24 and CD235a (DAKO, Kyoto, Japan); CD3, CD7, CD10, CD11b, CD20, CD41 and CD66c (Beckman Coulter, Fullerton, CA, USA); CD19 and CD56 (BD Biosciences, San Jose, CA, USA); CD4, CD14, CD33 and CD127 (eBioscience, San Diego, CA, USA); CD45RA (Southern Biotech, Birmingham, AL, USA); a Brilliant Violet 510 (BV510)-conjugated anti-CD45 mAb (BioLegend, San Diego, CA, USA); a Brilliant Violet 421 (BV421)-conjugated anti$\mathrm{CD} 34 \mathrm{mAb}$ (BioLegend), apophycocyanin (APC)-conjugated anti-CD133/1 mAb (Miltenyi Biotec, Bergish Gladbach, Germany), a phycoerythrin (PE)-conjugated anti-GPI-80 mAb (MBL Medical \& Biological Laboratories, Nagoya, Japan) and a $\mathrm{PE}-\mathrm{Cy} 7$-conjugated anti-CD38 mAb (BioLegend). The cells were then washed once with $\mathrm{PBS}^{-} /$FCS, and resuspended in a 7-amino-actinomycin D (7-AAD) (Beckman Coulter)-containing $\mathrm{PBS}^{-} / \mathrm{FCS}$ solution before the flow cytometric (FCM) analyses or FACS. The stained cells were then sorted into four fractions, including 18Lin ${ }^{-} \mathrm{CD} 34^{+} \mathrm{CD} 38^{-} \mathrm{CD} 133^{+} \mathrm{GPI}-80^{+/-}$and $18 \mathrm{Lin}^{-} \mathrm{CD} 34^{-} \mathrm{CD} 133^{+} \mathrm{GPI}-80^{+/-}$cells, using a FACSAriaII and a FACSAriaIII (BD Biosciences) (Fig. 1a-f). The purity of sorted cells was always confirmed by a post-sorting purity analysis. In order to define the $\mathrm{CD} 34^{-}$fraction for flow cytometric analyses, the gate was set based on the Fluorescent Minus One (FMO) control.

The surface marker expression of purified HSC populations. The expression of CD90, CD49f, CD93 and CD184 (CXCR4) on the surface of $18 \mathrm{Lin}^{-} \mathrm{CD} 34^{+} \mathrm{CD} 38$ ${ }^{-} \mathrm{CD} 133^{+} \mathrm{GPI}-80^{+}$and $18 \mathrm{Lin}^{-} \mathrm{CD} 34^{-} \mathrm{CD} 133^{+} \mathrm{GPI}-80^{+}$cells was analyzed using FACSCantoII (BD Biosciences). Human CB-derived $\mathrm{Lin}^{-}$cells obtained from individual samples $(n=7)$ were stained with a mixture of FITC-conjugated 18 Lin $\mathrm{mAbs}$, PE-conjugated anti-GPI- $80 \mathrm{mAbs}$, PE-Cy7-conjugated anti-CD38 $\mathrm{mAb}$, APC-conjugated anti-CD133/1 mAb, APC-Cy7-conjugated anti-CD34 mAb (BioLegend), BV510-conjugated anti-CD45 mAb and biotin-conjugated anti-CD90 (BioLegend), CD49f (BioLegend), CD184 (BioLegend) or CD93 mAb (OriGene). Biotin-conjugated $\mathrm{mAbs}$ were then reacted with BV421-conjugated streptavidin for $30 \mathrm{~min}$ at $4^{\circ} \mathrm{C}$. The samples were washed twice with $\mathrm{PBS}^{-} / \mathrm{FCS}$ followed by 7 -AAD staining before the analysis. The positive gate for the BV421 fluorescence channel was defined according to the FMO control.

Isolation of target cells for single-cell analyses. In order to analyze the singlecell gene expression profiles, CB-derived single CD $34^{+}$HSCs and CD $34^{-}$HSCs were isolated by FACSAriaII with the automated cell deposition unit (ACDU). Single CD90 ${ }^{+}$HSCs, MPPs, multi-lymphoid progenitors (MLPs), CMPs, granulocyte and monocyte progenitors (GMPs), megakaryocyte and erythrocyte progenitors (MEPs), erythroblasts, monocytes/macrophages, megakaryocytes, B cells and $\mathrm{T}$ cells were also isolated in accordance with previous reports ${ }^{2,3}$ by FACS. The details of the immunophenotypes of these fractions of cells are described in Supplementary Data 6.

An analysis of the morphology of the highly purified cells. Portions of $18 \mathrm{Lin}$ ${ }_{-}^{-} \mathrm{CD} 34^{+} \mathrm{CD} 38^{-} \mathrm{CD} 133^{+} \mathrm{GPI}-80^{+/-}$and $18 \mathrm{Lin}^{-} \mathrm{CD} 34^{-} \mathrm{CD} 133^{+} \mathrm{GPI}-80^{+/-}$cells were cytospun onto a slide glass. They were then stained with May-GrunwaldGiemsa for morphological analysis. The images of the cells were recorded using an inverted microscope system (BZ-9000, Keyence, Osaka, Japan) with a ×100 Apo oil objective lens (Fig. 1g)

An analysis of colony-forming capacity of single cells. Single $18 \mathrm{Lin}^{-} \mathrm{CD} 34^{+}$ $\mathrm{CD} 38^{-} \mathrm{CD} 133^{+} \mathrm{GPI}-80^{+/-}$or $18 \mathrm{Lin}^{-} \mathrm{CD} 34^{-} \mathrm{CD} 133^{+} \mathrm{GPI}-80^{+9-}$ cells were sorted into a 96-well flat-bottomed plate (Corning Inc., Corning, NY, USA) by the FACSAriaII with the ACDU, as reported ${ }^{56}$. Each well contained $50 \mu \mathrm{L}$ of our standard methylcellulose culture medium containing 30\% FCS (Biosera, Kansas, MO, USA) and 6 cytokines (thrombopoietin [TPO], stem cell factor [SCF] [R\&D Systems, Minneapolis, MN, USA], interleukin ${ }^{-} 3$ [IL-3], granulocyte/macrophage colony-stimulating factor [GM-CSF], granulocyte colony-stimulating factor [GCSF] and erythropoietin [Epo]), as reported ${ }^{21,22,34,53}$. TPO, GM-CSF, G-CSF, IL-3 and Epo were kindly provided by Kyowa Hakko Kirin Company (Tokyo, Japan). The plates were cultured for 10 to 14 days and then assayed as reported previously ${ }^{21,22,33,35,36,56}$. We analyzed various types of colony-forming cells (CFCs), including megakaryocyte-containing CFCs, as reported ${ }^{21,22,33,35,36,56}$. We picked up all of the colonies derived from single-cells under an inverted microscope. Cytospin preparations were made using Cytospin (Thermo Fisher Scientific, Waltham, MA, USA) for all colonies picked up from a total of eight 96-well flatbottomed plates. These cytospin preparations were stained with May-GrunwaldGiemsa for a morphological analysis. We identified neutrophils (n), macrophages (m), eosinophils (e), erythroblasts/erythrocytes (E) and megakaryocytes (M) and classified each colony as a single and/or multi-lineage one. Each colony type was classified as follows: colony-forming unit-granulocyte (CFU-G) containing n; colony-forming unit-macrophage (CFU-M) containing $\mathrm{m}$; colony-forming unitgranulocyte/macrophage (CFU-GM) containing $\mathrm{nm}$, ne or nme; colony-forming unit-eosinophil (CFU-Eo) containing e; burst-forming unit-erythroid (BFU-E) containing E; colony-forming unit-megakaryocyte (CFU-Meg) containing M; colony-forming unit-erythrocyte/megakaryocyte (CFU-EM) containing E and $\mathrm{M}$; colony-forming unit-mixed (CFU-Mix) containing $\mathrm{nE}, \mathrm{nM}, \mathrm{mM}, \mathrm{nmE}, \mathrm{nEM}$ nmM, neE, neM, nmEM or nmeEM (Supplementary Fig. 2).

Single-cell proliferation assay. Single $18 \mathrm{Lin}^{-\mathrm{CD}} 34^{+} \mathrm{CD} 38^{-} \mathrm{CD} 133^{+} \mathrm{GPI}-80^{+}$ $18 \mathrm{Lin}^{-} \mathrm{CD} 34^{-} \mathrm{CD} 133^{+} \mathrm{GPI}-80^{+}$and $18 \mathrm{Lin}^{-} \mathrm{CD} 34^{+} \mathrm{CD} 38^{\text {high }}$ cells were sorted using the ACDU into 60-well MiniTray (Thermo Fisher Scientific) which contained StemPro-34 SFM plus GlutaMax (1:100, Thermo Fisher Scientific) supplemented with a cocktail of 2 cytokines $(100 \mathrm{ng} / \mathrm{mL}$ TPO and $50 \mathrm{ng} / \mathrm{mL}$ SCF: referred to as basal medium), or with 10\% FCS (Biosera) added and supplemented with the a cocktail of 7 cytokines $(100 \mathrm{ng} / \mathrm{mL}$ TPO, $50 \mathrm{ng} / \mathrm{mL} \mathrm{SCF}, 50 \mathrm{ng} / \mathrm{mL}$ fms-like tyrosine kinase-3 ligand (FL) [Cell Signaling Technology, Beverly, MA, USA], 20 $\mathrm{ng} / \mathrm{mL}$ of G-CSF, $10 \mathrm{ng} / \mathrm{mL}$ of GM-CSF, $10 \mathrm{ng} / \mathrm{mL}$ IL-3 and $10 \mathrm{ng} / \mathrm{mL}$ IL-6 [Peprotech, Rocky Hill, NJ, USA]; referred to as complete medium) at $37^{\circ} \mathrm{C}$ under $5 \% \mathrm{CO}_{2}$ in air. The first and second cell division times were assessed by microscopic observation at $12 \mathrm{~h}$ intervals from 30 to $144 \mathrm{~h}$.

Cell cycle analyses. The cell cycle status of the abovementioned CB-derived highly purified HSC populations, such as $18 \mathrm{Lin}^{-} \mathrm{CD} 34^{+} \mathrm{CD} 38^{-} \mathrm{CD} 133^{+} \mathrm{GPI}-80^{+/-}$and $18 \mathrm{Lin}^{-} \mathrm{CD} 34^{-} \mathrm{CD} 133^{+} \mathrm{GPI}-80^{+/-}$cells were analyzed as mentioned below. As controls, the cell cycle status of CB- and BM-derived CD $90^{+}$HSCs, MPPs, MLPs and $\mathrm{Lin}^{-} \mathrm{CD} 34^{+} \mathrm{CD} 38^{\text {high }}$ cells was also analyzed. These hematopoietic stem/ progenitor cell (HSPCs) were obtained by FACS as follows; cryopreserved CB and $\mathrm{BM}$ samples were thawed and $\mathrm{Lin}^{-}$cells were immediately separated using an EasySep Human Progenitor Cell Enrichment Kit as described above. Immunomagnetically enriched $\mathrm{Lin}^{-}$cells were stained with surface markers by a cocktail of fluorochrome-conjugated mAbs as shown in Supplementary Data 5. Intracellular staining was then carried out using a BD Cytofix/Cytoperm Kit (BD Bioscience) in accordance with the manufacturer's instruction. The cells were fixed with Cytofix/ Cytoperm buffer (BD Bioscience) for $10 \mathrm{~min}$ at $4{ }^{\circ} \mathrm{C}$. Subsequently, the cells were placed into PermWash buffer (BD Bioscience) and then reacted with PE-Cy7conjugated anti-human Ki-67 mAb (1:25, BioLegend) and 7-AAD (1:50) at $4{ }^{\circ} \mathrm{C}$ for overnight. The expressions of surface markers and Ki-67 antigens and the DNA 
content in each fraction of cells were analyzed by an eight-color FCM (FACSCanto II). $G_{0}, G_{1}$ and $S / G_{2} / M$ gates were defined according to the FMO control.

NOG and NSG mice. Female six-week-old NOD.Cg-Prkdc ${ }^{\text {scid }} \mathrm{Il} 2 \mathrm{rg}^{\mathrm{tm} 1 \mathrm{Sug}} / \mathrm{Jic}$ $(\mathrm{NOG})^{57}$ and NOD.Cg-Prkdc ${ }^{\mathrm{scid}} \mathrm{Il} 2 \mathrm{rg}^{\mathrm{tm} 1 \mathrm{Wjl}} / \mathrm{SzJ}$ (NSG) ${ }^{58}$ mice were purchased from the Central Institute of Experimental Animals (Kawasaki, Japan) and Charles River Laboratories Japan, Inc. (Yokohama, Japan), respectively. All mice were handled under sterile conditions and maintained in germ-free isolators in the Central Laboratory Animal Facilities of Kansai Medical University. In order to reduce the oxidative stress, mice were given feed containing $1.3 \% \mathrm{~N}$-acetyl-Lcysteine (NAC) for the entire repopulation period, as previously reported ${ }^{59}$. The animal experiments were approved by the Animal Care Committees of Kansai Medical University. NOG and NSG mice (8-week-old) were sub-lethally irradiated ( $2.5 \mathrm{~Gy}$ using a ${ }^{137} \mathrm{Cs}-\gamma$ irradiator) immediately before all of the transplantation studies. Intra-BM injection of purified cells. IBMI was carried out as reported pre-
viously $18,21,22,25,33-36,60$. Briefly, after sterilization of the skin around the left knee joint, the knee was flexed to 90 degrees and the proximal side of the tibia was drawn to the anterior. A 26-gauge needle was inserted into the joint surface of the tibia through the patellar tendon and then inserted into the BM cavity. Using a Hamilton microsyringe, the specified number of cells per $10 \mu \mathrm{L}$ of $\alpha$-medium plus $5 \%$ FCS were carefully injected from the bone hole into the BM cavity.

SCID-repopulating cell assay by FCM. The SRC assays were performed by the previously reported method ${ }^{18,21,22,25,34-36,60}$. In this study, a specified number of $18 \mathrm{Lin}^{-} \mathrm{CD} 34^{+} \mathrm{CD} 38^{-} \mathrm{CD} 133^{+} \mathrm{GPI}-80^{+/-}$and $18 \mathrm{Lin}^{-} \mathrm{CD} 34^{-} \mathrm{CD} 133^{+} \mathrm{GPI}-80^{+/-}$ cells were transplanted by IBMI into eight-week-old NOG or NSG mice. Human hematopoietic repopulations in the mouse BMs were serially analyzed 12 and 18 weeks after transplantation by the BM aspiration method ${ }^{18,21,22,25,34-36,60}$. The aliquots of $\mathrm{BM}$ aspirates were stained with a Pacific Blue (PB)-conjugated antihuman CD45 mAb (BioLegend), a PE-Cy7-conjugated anti-mouse CD45.1 mAb (Beckman Coulter), FITC-conjugated anti-human CD19 mAb, PE-conjugated antihuman CD33 mAb (Beckman Coulter), APC-conjugated anti-human CD34 mAb (BD Biosciences) and 7-AAD and were analyzed by six-color FCM (FACS CantoII). At weeks 20 to 22 , the mice were killed, and the BM cells were collected by crushing the femurs and tibiae from each of mice in a mortar. The cells from the $\mathrm{PB}$, spleen (SP) and thymus (Thy) of these mice were also collected. The repopulation of human hematopoietic cells in the murine BM, PB, SP and Thy were determined by detecting the number of $7-\mathrm{AAD}^{-}$cells positively stained with $\mathrm{PB}$ conjugated anti-human CD45 mAb by six-color FCM (FACS CantoII). The cells were also stained with a PE-Cy7-conjugated anti-mouse CD45.1 mAb (Beckman Coulter); FITC- or BV510-conjugated anti-human CD3 (BM, Thy), CD19 (BM, $\mathrm{PB}, \mathrm{SP}), \mathrm{CD} 11 \mathrm{~b}(\mathrm{BM})$ and CD235a (BM) mAbs; PE-conjugated anti-human CD4 (Thy) (eBioscience), CD33 (BM, PB, SP), CD14 (BM) and CD41 (BM, SP) mAbs (Beckman Coulter), and APC-conjugated anti-human CD8 (Thy) (eBioscience) and CD34 (BM, PB, SP) mAbs (BD Biosciences) for the detection of human stem/ progenitor, B-lymphoid, T-lymphoid and myeloid/monocytic hematopoietic cells. For the precise analysis of the NK-cell development in the spleen, the cells were stained with an FITC-conjugated anti-human CD56 mAb (BD Biosciences). In order to determine the human $\mathrm{CD}_{4} 5^{+}$gate for the transplantation analyses, $\mathrm{BM}$ tissue from NSG mice that did not receive human cells was used as a negative control and human cord blood-derived mononuclear cells were used as a positive control. In all transplantation experiments, the mice were scored as positive if more than $0.01 \%$ of the total murine $\mathrm{BM}$ cells were human $\mathrm{CD} 45^{+}$cells, as previously reported $^{22}$.

Secondary transplantation. For secondary transplantations, murine BM cells were obtained 19 to 23 weeks after the transplantation from pairs of the femurs and tibiae from engrafted primary recipient NOG/NSG mice receiving the abovementioned purified $18 \mathrm{Lin}^{-} \mathrm{CD} 34^{+} \mathrm{CD} 38^{-} \mathrm{CD} 133^{+} \mathrm{GPI}-80{ }^{+}$and $18 \mathrm{Lin}^{-} \mathrm{CD} 34$ ${ }^{-} \mathrm{CD} 133^{+} \mathrm{GPI}-80^{+}$cells. The secondary transplantation was then performed, as previously reported ${ }^{18,21,22,33,36}$. Briefly, $1 / 5$ of the whole BM cells were transplanted into both tibiae of secondary recipient mice by IBMI. Some of the whole BM cells were stained with the FITC-conjugated $18 \mathrm{Lin}$ mAbs, BV510-conjugated antiCD45 mAb, BV421-conjugated anti-CD34 mAb, PE-Cy7-conjugated anti-CD38 $\mathrm{mAb}, \mathrm{APC}$-conjugated anti-CD133/1 $\mathrm{mAb}$ and PE-conjugated anti-GPI- $80 \mathrm{mAb}$. The $18 \mathrm{Lin}^{-} \mathrm{CD} 34^{+}$and $18 \mathrm{Lin}^{-} \mathrm{CD} 34^{-}$cells were then resorted and transplanted into secondary recipient mice. Expression of CD38, CD133 and GPI-80 on these $18 \mathrm{Lin}^{-} \mathrm{CD} 34^{+/-}$cells recovered from the engrafted primary recipient mice was analyzed by FCM. Finally, at 19 to 23 weeks after transplantation, presence of human $\mathrm{CD}^{+} 5^{+}$cells in the secondary recipients' BMs was analyzed by FCM, as described above.

In vivo limiting dilution analysis. To assess frequency of SRCs in $\mathrm{CB}$-derived $18 \mathrm{Lin}^{-} \mathrm{CD} 34^{+} \mathrm{CD} 38^{-} \mathrm{CD} 133^{+} \mathrm{GPI}-80^{+/-}$and $18 \mathrm{Lin}^{-} \mathrm{CD} 34^{-} \mathrm{CD} 133^{+} \mathrm{GPI}-80^{+1-}$ cells, various numbers of cells, the precise numbers of which are shown in Supplementary Data 1, were transplanted into NSG mice by IBMI, as previously reported $18,21,22,25,33$. The human cell repopulation in the mouse BM was analyzed at 20 weeks after transplantation by FCM.

Single-cell transplantation. Single $18 \mathrm{Lin}^{-} \mathrm{CD} 34^{+} \mathrm{CD} 38^{-} \mathrm{CD} 133^{+} \mathrm{GPI}-80^{+}$or $18 \mathrm{Lin}^{-} \mathrm{CD}^{-} 4^{-} \mathrm{CD} 133^{+} \mathrm{GPI}-80^{+}$cells were sorted into a 60 -well MiniTray in $20 \mu \mathrm{L}$ of $\alpha$-medium with $10 \%$ FCS using the ACDU with a FACSAriaII. After sorting, the cells were incubated in the $\mathrm{CO}_{2}$ incubator for $1 \mathrm{~h}$, and visualized under an inverted microscope. Each cell was transferred into a Hamilton microsyringe under the inverted microscope. Wells were re-visualized to confirm that the cell had been successfully transferred into the syringe. In another independent experiment, we confirmed the viability ( $>99 \%$ ) of single-sorted cells by Trypan blue dye exclusion. We next analyzed efficiency of our single-cell transplantation method. We sorted single $18 \mathrm{Lin}^{-} \mathrm{CD} 34^{+} \mathrm{CD} 38^{-} \mathrm{CD} 133^{+} \mathrm{GPI}-80^{+}$or $18 \mathrm{Lin}^{-} \mathrm{CD} 34^{-} \mathrm{CD} 133^{+} \mathrm{GPI}-80^{+}$ cells into a 60-well MiniTray. After transferring the cells into a Hamilton microsyringe, the cells were expunged into a new 60-well MiniTray and spun down and visualized. We observed a single cell in $87 \%$ of the wells $(n=117)$, indicating that only $87 \%$ of recipient mice transplanted with single $18 \mathrm{Lin}^{-} \mathrm{CD} 34^{+} \mathrm{CD} 38^{-} \mathrm{CD} 133$ ${ }^{+} \mathrm{GPI}-80^{+}$or $18 \mathrm{Lin}^{-} \mathrm{CD} 34^{-} \mathrm{CD} 133^{+} \mathrm{GPI}-80^{+}$cells actually received a single cell. This efficiency was taken into consideration in our evaluation of the single-cell transplantation data of LDA.

Single-cell initiated serial transplantation. We performed secondary transplantations from primary engrafted recipient mice that received single purified $18 \mathrm{Lin}^{-} \mathrm{CD} 34^{+} \mathrm{CD} 38^{-} \mathrm{CD} 133^{+} \mathrm{GPI}-80^{+}$and $18 \mathrm{Lin}^{-} \mathrm{CD} 34^{-} \mathrm{CD} 133^{+} \mathrm{GPI}-80^{+}$cells at 21 to 23 weeks after transplantation. In these cases, we transplanted $2 / 5$ of the whole BM cells into both tibiae of two secondary recipient mice by IBMI. Tertiary transplantation was performed in the same way as secondary transplantations; we transplanted $2 / 5$ of the whole BM cells obtained from secondary recipient mice into both tibiae of two tertiary recipient mice by IBMI. The human CD $45^{+}$cell repopulation in the secondary and tertiary recipient mice was analyzed at 12 weeks after the transplantation by the BM aspiration technique. At 21 to 23 weeks after transplantation, the mice were killed and the BM cells were collected by crushing the femurs and tibiae from each of the mice in a mortar. The cells from the PB, SP and Thy of these mice were also collected. The repopulation of human hematopoietic cells in the murine BM, PB, SP and Thy were determined by detecting the number of 7-AAD ${ }^{-}$cells positively stained with $\mathrm{PB}$-conjugated anti-human $\mathrm{CD} 45$ $\mathrm{mAb}$ by six-color FCM (FACS CantoII). The cells were also stained with a PE-Cy7conjugated anti-mouse CD45.1 mAb (Beckman Coulter); FITC- or BV510conjugated anti-human CD3 (BM, Thy), CD19 (BM, PB, SP), CD11b (BM) and CD235a (BM) mAbs; PE-conjugated anti-human CD4 (Thy) (eBioscience), CD33 (BM, PB, SP), CD14 (BM) and CD41 (BM) mAbs (Beckman Coulter), and APC conjugated anti-human CD8 (Thy) (eBioscience) and CD34 (BM, PB, SP) mAbs (BD Biosciences) for the detection of human stem/progenitor, B-lymphoid, Tlymphoid and myeloid/monocytic hematopoietic cells. For the precise analysis of the NK-cell development in the spleen, the cells were stained with an FITC-conjugated anti-human CD56 mAb (BD Biosciences).

Real-time reverse transcription polymerase chain reaction. The primers were designed using the NCBI/Primer BLAST (http://www.ncbi.nlm.nih.gov/tools/ primer-blast/) and Primer3 web tool (http://primer3.ut.ee/). The primer pairs used for RT-PCR are shown in Supplementary Data 7. The primer melting temperature (Tm) of all primers was set at 59 to $63^{\circ} \mathrm{C}$. We designed both the first (for preamplification) and second (for real-time PCR) primer pairs for individual target genes. Both the forward and reverse second primers were designed to slide at least three bases inside of the amplicon produced by the first primer pairs.

To validate the gene amplification by each primer pair, total RNA was extracted from CB-derived mononuclear cells using an RNeasy Plus Micro kit (QIAGEN, Hilden, Germany). Reverse transcription was then carried out using an iScript cDNA synthesis kit (Bio-Rad Laboratories, Hercules, CA, USA) as follows: 5 min at $25^{\circ} \mathrm{C}, 30 \mathrm{~min}$ at $42^{\circ} \mathrm{C}$ and $5 \mathrm{~min}$ at $85^{\circ} \mathrm{C}$. The cDNA was then mixed with Power SYBR green Master Mix (Thermo Fisher Scientific), and real-time PCR were then carried out by Rotor-Gene Q (QIAGEN). PCR amplicons were subjected to gel electrophoresis, and the size of the PCR amplicon was validated by comparison with the predicted product size, which was calculated using NCBI/Primer BLAST and Primer3 web tools.

To compare the expression of the VNN2 gene between $18 \mathrm{Lin}^{-} \mathrm{CD} 34^{+} \mathrm{CD} 38$ ${ }^{-} \mathrm{CD} 133^{+} \mathrm{GPI}-80^{+/-}$and $18 \mathrm{Lin}^{-} \mathrm{CD} 34^{-} \mathrm{CD} 133^{+} \mathrm{GPI}-80^{+/-}$cells, total RNA was extracted from $1.4 \times 10^{4}$ of each fraction of cells. As positive and negative controls $1.4 \times 10^{4}$ cells of CB-derived neutrophils and THP-1 cells were used. Reverse transcriptions and real-time PCR were then carried out as described above. The primer sequences for the VNN2 genes were as follows: forward primer (5'-TGGA CGGCCAGTAGAAACTGC-3'), reverse primer (5'-ACCAAACGCCCATCTTT CAGC- $\left.3^{\prime}\right)$. The expression of VNN2 was normalized by that of ACTB ( $\beta$-actin) in each sample. The relative gene expression was calculated by using the $2^{-\Delta \Delta C}$ method. All primers were purchased from Thermo Fisher Scientific.

Cell line. THP-1 cell line was purchased from RIKEN BRC CELL BANK (Tsukuba, Japan). 
Single-cell gene expression analyses. First, single $18 \mathrm{Lin}^{-} \mathrm{CD} 34^{+} \mathrm{CD} 38^{-} \mathrm{CD} 133^{+}$ GPI- $80^{+}$or $18 \mathrm{Lin}^{-} \mathrm{CD} 34^{-} \mathrm{CD} 133^{+} \mathrm{GPI}-80^{+}$cells were sorted by FACS into $96-$ well PCR plates (Thermo Fisher Scientific) containing $9 \mu \mathrm{L}$ of Cells Direct OneStep qPCR master mixture (Thermo Fisher Scientific) combined with a mixture of pre-amplification primers (listed in Supplementary Data 7). The cells were then immediately lysed by using a vortex mixer. Reverse transcription was carried out for $15 \mathrm{~min}$ at $50^{\circ} \mathrm{C}$ and $2 \mathrm{~min}$ at $95^{\circ} \mathrm{C}$. Subsequently, pre-amplification was carried out for 20 cycles as follows: $15 \mathrm{~s}$ at $95^{\circ} \mathrm{C}$ and $4 \mathrm{~min}$ at $60^{\circ} \mathrm{C}$. Pre-amplified cDNA were stored at $-80^{\circ} \mathrm{C}$ until immediately before the next step, when it was treated with $4 \mathrm{U} / \mu \mathrm{L}$ of Exonuclease I (New England BioLab Inc., Ipswich, MA, USA) for $30 \mathrm{~min}$ at $37^{\circ} \mathrm{C}$ followed by treatment for $15 \mathrm{~min}$ at $80^{\circ} \mathrm{C}$. The diluted preamplified cDNA was loaded onto 96.96 DynamicArray chips (Fluidigm, South San Francisco, CA, USA) and mixed with Assay Loading Reagent (Fluidigm) and mixture of target gene-specific nested primers (listed in Supplementary Data 7). Single-cell real-time PCR was then performed using a Biomark HD System (Fluidigm) in accordance with the manufacturer's instruction. Real-time PCR was carried out at $70^{\circ} \mathrm{C}$ for $40 \mathrm{~min}, 60^{\circ} \mathrm{C}$ for $30 \mathrm{~s}$ and $95^{\circ} \mathrm{C}$ for $1 \mathrm{~min}$ followed by 35 cycles of amplification $\left(96^{\circ} \mathrm{C}\right.$ for $5 \mathrm{~s}$ and $60^{\circ} \mathrm{C}$ for $\left.20 \mathrm{~s}\right)$. Ct values were calculated using the BioMark HD System Real-time PCR Analysis software program (Fluidigm) and filtered according to a set of quality control rules.

To confirm the presence of cells, we used four reference genes: PGK1, PTPRC, $A C T B$ and GAPDH. The cells with $\mathrm{Ct}>24$ cycles for PGK1 and PTPRC and $>20$ cycles for $A C T B$ and $G A P D H$, were excluded from the data. In addition, the $\mathrm{CD} 34^{+}$ HSCs and $\mathrm{CD} 90^{+}$HSCs with Ct values $>24$ cycles for $\mathrm{CD} 34$ were also excluded from the data. Other genes with $\mathrm{Ct}$ values $>24$ cycles in all target cells were excluded from the data. This resulted in a single-cell gene expression data set (83 genes including 4 reference genes) consisting of 126 cells $\left(3318 \mathrm{Lin}^{-} \mathrm{CD} 34^{+}\right.$ CD $38^{-} \mathrm{CD} 133^{+}{ }^{-} \mathrm{GPI}-80^{+}$cells, $2318 \mathrm{Lin}^{-} \mathrm{CD} 34^{-} \mathrm{CD} 133^{+} \mathrm{GPI}-80^{+}$cells, $5 \mathrm{CD}^{+} 0^{+}$ HSCs, 9 MPP, 8 CMP, 6 MLP, 7 MEP, 11 GMP, 5 erythroblasts, 5 megakaryocytes, $4 \mathrm{~T}$ cells, $4 \mathrm{~B}$ cells and 6 monocytes/macrophages) from a total of 2 chip runs. These experiments were performed independently three times. The data were analyzed using the SINGuLAR Analysis Toolset software program (Fluidigm). A PCA and unsupervised hierarchical clustering analysis were performed in accordance with the manufacturer's instruction. PCAs were performed on data from CD $34^{+}$HSCs, CD $34^{-}$HSC and CD $90^{+}$HSCs. Unsupervised hierarchical clustering analyses were performed on data derived from all 126 cells. Four reference genes were excluded from these analyses. The violin plots were depicted using the SINGuLAR Analysis Toolset software program. In additional experiments, we analyzed single-cell gene expression profiles of $\mathrm{CD} 34^{+/-} \mathrm{HSCs}$ and various progenitors, including MEPs, as described above.

Microarray analyses. Total RNA from $3.4 \times 10^{4}$ to $5 \times 10^{4} 18 \mathrm{Lin}^{-} \mathrm{CD} 34^{+} \mathrm{CD} 38$ ${ }^{-} \mathrm{CD} 133^{+} \mathrm{GPI}-80^{+}, 18 \mathrm{Lin}^{-} \mathrm{CD} 34^{-} \mathrm{CD} 133^{+} \mathrm{GPI}-80^{+}$and $18 \mathrm{Lin}^{-} \mathrm{CD} 34^{+} \mathrm{CD} 38$ ${ }^{-} \mathrm{CD}_{133}{ }^{-}$cells were extracted using an RNeasy Plus Micro kit (QIAGEN). The RNA quality was assessed using the Agilent Model 2100 Bioanalyzer (Agilent Technologies, Palo Alto, CA, USA). Total RNA (1-6.5 ng) was amplified using an Ovation Pico WTA System V2 (NuGEN, San Carlos, CA, USA). The amplified RNA was labeled with Cy3 using a SureTag Complete DNA Labeling Kit (Agilent Technologies). Subsequently, the amplified RNA was hybridized with a SurePrint G3 Human Gene Expression $8 \times 60 \mathrm{~K}$ v3 Microarray platform (Agilent Technologies), and the data were scanned in accordance with the manufacturer's protocol. In order to normalize the data between each of the samples, the mean signal intensity of the individual samples was adjusted to 2500. A gene set enrichment analysis (GSEA) was also performed in accordance with previous reports ${ }^{61}$.

Ex vivo expansion of CB-derived CD34 ${ }^{-}$HSCs. $18 \mathrm{Lin}^{-} \mathrm{CD} 34^{-} \mathrm{CD} 133^{+} \mathrm{GPI}-80^{+}$ cells ( 2850 cells/well, triplicate culture) were plated onto 24 -well culture plate and cultured in StemSpan SFEM (StemCell Technologies) supplemented with a cocktail of cytokines, including $50 \mathrm{ng} / \mathrm{mL}$ TPO, $100 \mathrm{ng} / \mathrm{mL}$ SCF and $100 \mathrm{ng} / \mathrm{mL}$ FL and 10 $\mu \mathrm{g} / \mathrm{mL}$ low-density lipoprotein (EDM Millipore, Temecula, CA, USA) as recently reported $^{45,46}$. StemRegenin ${ }^{-1}$ (SR-1) (StemCell Technologies) and Pyrimidoindole derivative (UM171) (StemCell Technologies) were dissolved in dimethyl sulfoxide (DMSO) (Nacalai Tesque). Subsequently, 0.1\% DMSO (control), $750 \mathrm{nM} \mathrm{SR-1}$ and $35 \mathrm{nM}$ UM171 were added to the culture medium at the start of these cultures. At Day 12, the cultured cells were collected and stained with a mixture of the following mAbs: FITC-conjugated 12Lin mAbs including CD2, CD3, CD4, CD7, CD8, CD10, CD11b, CD14, CD19, CD20, CD56 and CD235a, a FITC-conjugated anti-CD45RA $\mathrm{mAb}$, a PE-conjugated anti-GPI- $80 \mathrm{mAb}$, PE-Cy7-conjugated anti-CD38 $\mathrm{mAb}$, an APC-conjugated anti-CD133/1 mAb, a BV421-conjugated anti-CD34 mAb and a

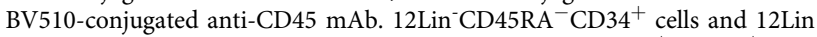
${ }^{-} \mathrm{CD} 45 \mathrm{RA}^{-} \mathrm{CD} 34^{-}$cells produced from $18 \mathrm{Lin}^{-} \mathrm{CD} 34^{-} \mathrm{CD} 133^{+} \mathrm{GPI}-80^{+}$cells were then sorted and collected by FACSAriaIII. The CD34-negative cell gate was defined according to the FMO control. Twelve $\mathrm{Lin}^{-}$and CD45RA-negative cell gates were also set according to the FMO controls. In order to prevent the loss of CD34 ${ }^{+}$ SRCs, the CD34-positive cell gate was set adjacent to the CD34-negative cell gate. Varying numbers of $12 \mathrm{Lin}^{-} \mathrm{CD} 45 \mathrm{RA}^{-} \mathrm{CD} 34^{+}$cells generated under each culture condition were transplanted into six to eight NSG mice/group by IBMI. All 12Lin ${ }^{-} \mathrm{CD} 45 \mathrm{RA}^{-} \mathrm{CD} 34^{-}$cells harvested under each culture condition were split and transplanted into six or seven NSG mice by IBMI. The frequencies of SRC in the culture-generated $12 \mathrm{Lin}^{-} \mathrm{CD} 45 \mathrm{RA}^{-} \mathrm{CD} 34^{+}$cells were estimated using an ELDA web tool ${ }^{62}$, as described in the Statistical analyses. The details of the design of LDA for cultured cells are described in Supplementary Fig. 13a. At 6 weeks after transplantation, the human multi-lineage hematopoietic repopulation (including $\mathrm{CD}_{3} 4^{+}, \mathrm{CD}_{1} 9^{+}$and $\mathrm{CD} 33^{+}$cells) in the $\mathrm{BM}$ of the left tibiae of each mouse (injected site) were analyzed by a BM aspiration technique.

Statistical analyses. In Fig. $1 \mathrm{~h}$ and Supplementary Fig. $4 c$, and Supplementary Fig. 13c, d, and f, differences between each pair of all the means were examined by Tukey's multiple comparison procedure. In Fig. 1i, the differences in the colony-forming efficiency of each cell types were examined by a two-way analysis of variance. In Fig. 2b,c and Supplementary Fig. 11, the difference in the means between each pair was examined using a two-tailed Student's $t$-test. In Supplementary Fig. $4 \mathrm{~d}$ and Supplementary Fig. $8 \mathrm{a}$ and b, the significance of differences was determined using the Mann-Whitney $U$ test. Differences were considered statistically significant at a confidence level of $<0.05$. In Fig. $4 a$, the regions of the $\mathrm{CD} 34^{+}$and $\mathrm{CD} 34^{-}$HSCs on the PCA plot were determined by a Fisher's linear discriminant analysis. In the LDA (Supplementary Fig. 5 and Supplementary Fig. 13e), the frequencies of SRCs were calculated as previously reported $^{62}$

Data availability statement. We presented microarray data in Fig. 6, Supplementary Fig. 11 and Supplementary Fig. 12. Microarray expression data are available at NCBI GEO: GSE100354.

Received: 10 May 2017 Accepted: 29 April 2018

Published online: 06 June 2018

\section{References}

1. Doulatov, S., Notta, F., Laurenti, E. \& Dick, J. E. Hematopoiesis: a human perspective. Cell Stem Cell 10, 120-136 (2012).

2. Doulatov, S. et al. Revised map of the human progenitor hierarchy shows the origin of macrophages and dendritic cells in early lymphoid development. Nat. Immunol. 11, 585-593 (2010).

3. Notta, F. et al. Isolation of single human hematopoietic stem cells capable of long-term multilineage engraftment. Science 333, 218-221 (2011).

4. Kondo, M. et al. Biology of hematopoietic stem cells and progenitors: Implications for clinical application. Annu. Rev. Immunol. 21, 759-806 (2003).

5. Korbling, M. \& Estrov, Z. Adult stem cells for tissue repair-A new therapeutic concept? N. Engl. J. Med. 349, 570-582 (2003).

6. Bryder, D., Rossi, D. J. \& Weissman, I. L. Hematopoietic stem cells. Am. J. Pathol. 169, 338-346 (2006).

7. Ratajczak, M. Z. Phenotypic and functional characterization of hematopoietic stem cells. Curr. Opin. Hematol. 15, 293-300 (2008).

8. Kiel, M. J. et al. SLAM family receptors distinguish hematopoietic stem and progenitor cells and reveal endothelial niches for stem cells. Cell 121, 1109-1121 (2005)

9. Chen, J. et al. Enrichment of hematopoietic stem cells with SLAM and LSK markers for the detection of hematopoietic stem cell function in normal and Trp53 null mice. Exp. Hematol. 36, 1236-1243 (2008).

10. Krause, D. S., Fackler, M. J., Civin, C. I. \& May, W. S. CD34: Structure, biology, and clinical utility. Blood 87, 1-13 (1996).

11. Osawa, M., Hanada, K., Hamada, H. \& Nakauchi, H. Long-term lymphohematopoietic reconstitution by a single $\mathrm{CD} 34^{-}$low/negative hematopoietic cell. Science 273, 242-245 (1996).

12. Nakamura, Y. et al. Ex vivo generation of CD34 positive cells from CD34 negative hematopoietic cells. Blood 94, 4053-4059 (1999).

13. Zanjani, E. D. et al. Human bone marrow CD34- cells engraft in vivo and undergo multilineage expression that includes giving rise to $\mathrm{CD} 34^{+}$cells. Exp. Hematol. 26, 353-360 (1998).

14. Danet, G. H. et al. C1qRp defines a new human stem cell population with hematopoietic and hepatic potential. Proc. Natl Acad. Sci. USA 99, 10441-10445 (2002)

15. Dick, J. E. Normal and leukemic human stem cells assayed in SCID mice. Semin. Immunol. 8, 197-206 (1996).

16. Vormoor, J. et al. Immature human cord blood progenitors engraft and proliferate to high levels in severe combined immune-deficient mice. Blood $\mathbf{8 3}$ 2489-2497 (1994)

17. Bhatia, M. et al. A newly discovered class of human hematopoietic cells with SCID-repopulating activity. Nat. Med. 4, 1038-1045 (1998).

18. Wang, J. et al. SCID-repopulating cell activity of human cord blood-derived CD34- cells assured by intra-bone marrow injection. Blood 101, 2924-2931 (2003).

19. Sonoda, Y. Immunophenotype and functional characteristics of human primitive CD34-negative hematopoietic stem cells: The significance of the intra-bone marrow injection. J. Autoimmun. 30, 136-144 (2008). 
20. Sonoda, Y. in Adult Stem Cell Therapies: Alternatives to Plasticity (ed. Ratajczak, M. Z.) 53-77 (Humana Press, Springer, Berlin, 2014).

21. Ishii et al. Development of a high resolution purification method for precise functional characterization of primitive human cord blood-derived CD34-negative SCID-repopulating cells. Exp. Hematol. 39, 203-213 (2011).

22. Takahashi, M. et al. CD133 is a positive marker for a distinct class of primitive human cord blood-derived CD34-negative hematopoietic stem cells. Leukemia 28, 1308-1315 (2014).

23. Suzuki, K. et al. A novel glycosylphosphatidyl inositol-anchored protein on human leukocytes: a possible role for regulation of neutrophil adherence and migration. J. Immunol. 162, 4277-4284 (1999).

24. Yoshitake, H. et al. GPI-80, a $\beta 2$ integrin associated glycosylphosphatidylinositol-anchored protein, concentrates on pseudopodia without association with $\beta 2$ integrin during neutrophil migration. Immunobiol 208, 391-399 (2003).

25. Matsuoka, Y. et al. GPI-80 expression highly purifies human cord bloodderived primitive CD34-negative hematopoietic stem cells. Blood 128, 2258-2260 (2016).

26. Pietras, E. M., Warr, M. R. \& Passegue, E. Cell cycle regulation in hematopoietic stem cells. J. Cell Biol. 195, 709-720 (2011).

27. Jordan, C. T., Yamasaki, G. \& Minamoto, D. High-resolution cell cycle analysis of defined phenotypic subsets within primitive human hematopoietic cell populations. Exp. Hematol. 24, 1347-1355 (1996).

28. Yahata, T. et al. Quiescent human hematopoietic stem cells in the bone marrow niches organize the hierarchical structure of hematopoiesis. Stem Cells 26, 3228-3236 (2008).

29. Laurenti, E. et al. CDK6 levels regulate quiescence exit in human hematopoietic stem cells. Cell Stem Cell 16, 302-313 (2015).

30. Mikkola, H. K. A. \& Orkin, S. H. The journey of developing hematopoietic stem cells. Development 133, 3733-3744 (2006).

31. Robin, C. et al. Human placenta is a potent hematopoietic niche containing hematopoietic stem and progenitor cells throughout development. Cell Stem Cell 5, 385-395 (2009).

32. Dzierdak, E. \& Robin, C. Placenta as a source of hematopoietic stem cells. Trends Mol. Med. 16, 361-367 (2010).

33. Matsuoka, Y. et al. CD34 antigen and the MPL receptor expression defines a novel class of human cord blood-derived primitive hematopoietic stem cells. Cell Transplant. 26, 1043-1058 (2017).

34. Matsuoka, Y. et al. Human cord blood-derived CD34-negative hematopoietic stem cells (HSCs) are myeloid-biased long-term repopulating HSCs. Blood Cancer J. 5, e290 (2015).

35. Matsuoka, Y. et al. Prospectively isolated human bone marrow cell-derived MSCs support primitive human CD34-negative hematopoietic stem cells. Stem Cells 33, 1554-1565 (2015).

36. Kimura, T. et al. Identification of long-term repopulating potential of human cord blood-derived CD $34^{-} \mathrm{flt}^{-}$severe combined immunodeficiency-repopulating cells by intra-bone marrow injection. Stem Cells 25, 1348-1355 (2007).

37. Esser, M. A. G. et al. INFa activates dormant haematopoietic stem cells in vivo. Nature 458, 904-908 (2009).

38. Sato, T. et al. Interferon regulatory factor- 2 protects quiescent hematopoietic stem cells from type I interferon-dependent exhaustion. Nat. Med. 15, 696-700 (2009).

39. Gur-Cohen, S., Kollet, O., Esmon, C. T. \& Lapidot, T. Regulation of long-term repopulating hematopoietic stem cells by EPCR/PAR1 signaling. Ann. NY Acad. Sci. 1370, 65-81 (2016).

40. Ishibashi, T. et al. ESAM is a novel human hematopoietic stem cell marker associated with a subset of human leukemias. Exp. Hematol. 44, 269-281 (2016).

41. Anjos-Alfonso, F. et al. CD34 ${ }^{-}$cells at the apex of the human hematopoietic stem cell hierarchy have distinctive cellular and molecular signatures. Cell Stem Cell 13, 161-174 (2013).

42. Gluckman, E. et al. Milestones in umbilical cord blood transplantation. Br. J. Haematol. 154, 441-447 (2011).

43. Ballen, K. K., Gluckman, E. \& Broxmeyer, H. E. Umbilical cord blood transplantation: the first 25 years and beyond. Blood 122, 491-498 (2013).

44. Kerke, N. \& Antin, J. H. Hematopoietic stem cell transplantation donor sources in the 21 st century: choosing the ideal donor when a perfect match does not exist. Blood 124, 334-343 (2014).

45. Boitano, A. E. et al. Aryl hydrocarbon receptor antagonists promote the expansion of human hematopoietic stem cells. Science 329, 1345-1348 (2010).

46. Fares, I. et al. Cord blood expansion. Pyrimidoindole derivatives are agonists of human hematopoietic stem cell self-renewal. Science 345, 1509-1512 (2014).

47. Prashad, S. L. et al. GPI-80 defines self-renewal ability in hematopoietic stem cells during human development. Cell. Stem. Cell. 16, 80-87 (2015).
48. Giebel, B. et al. Segregation of lipid raft markers including CD133 in polarized human hematopoietic stem and progenitor cells. Blood 104, 2332-2338 (2004)

49. Bauer, N. et al. New insights into the cell biology of hematopoietic progenitors by studying prominin-1 (CD133). Cell Tissue Organs 188, 127-138 (2008).

50. Shultz, L. D., Ishikawa, F. \& Greiner, D. L. Humanized mice in translational biomedical research. Nat. Rev. Immunol. 7, 118-130 (2007).

51. Gekas, C. \& Graf, T. CD41 expression marks myeloid-biased adult hematopoietic stem cells and increases with age. Blood 121, 4463-4472 (2013).

52. Sanjuan-Pla, A. et al. Platelet-biased stem cells reside at the apex of the haematopoietic stem-cell hierarchy. Nature 502, 232-236 (2013).

53. Yamamoto, R. et al. Clonal analysis unveils self-renewing lineage-restricted progenitors generated directly from hematopoietic stem cells. Cell 154, 1112-1126 (2013).

54. Notta, F. et al. Distinct routes of lineage development reshape the human blood hierarchy across ontogeny. Science 351, aab2116 (2016).

55. Sanada, C. et al. Adult human megakaryocyte-erythroid progenitors are in the CD $34^{+}$CD $38^{\text {mid }}$ fraction. Blood 128, 923-933 (2016).

56. Tanimukai, S. et al. Recombinant human c-Mpl ligand (thrombopoietin) not only acts on megakaryocyte progenitors, but also on erythroid and multipotential progenitors in vitro. Exp. Hematol. 25, 1025-1033 (1997).

57. Ito, M. et al. NOD/SCID $/ \gamma \mathrm{c}^{\text {null }}$ mouse: an excellent recipient mouse model for engraftment of human cells. Blood 100, 3175-3182 (2002).

58. McDermott, S. P. et al. Comparison of human cord blood engraftment between immunocompromised mouse strains. Blood 116, 193-200 (2010).

59. Yahata, T. et al. Accumulation of oxidative DNA damage restricts the selfrenewal capacity of human hematopoietic stem cells. Blood 118, 2941-2950 (2011).

60. Kimura, T. et al. In vivo dynamics of human cord blood-derived CD34 SCID-repopulating cells using intra-bone marrow injection. Leukemia 24, 162-168 (2010).

61. Subramanian, S. et al. Gene set enrichment analysis: a knowledge-based approach for interpreting genome-wide expression profiles. Proc. Natl Acad. Sci. USA 102, 15545-15550 (2005).

62. Hu, Y. \& Smyth, G. K. ELDA: extreme limiting dilution analysis for comparing depleted and enriched populations in stem cell and other assays. J. Immunol. Methods 347, 70-78 (2009).

63. Orkin, S. H. \& Zon, L. I. Hematopoiesis: an evolving paradigm for stem cell biology. Cell 132, 631-644 (2008).

\section{Acknowledgements}

This work was supported by Grants-in-Aid for Scientific Research C (Grant Nos. 21591251, 24591432 and 16K09881) from the Ministry of Education, Culture, Sports, Science and Technology (MEXT) of Japan; a grant from the Science Frontier Program of the MEXT; a grant from the Strategic Research Base Development program for Private Universities from the MEXT; MEXT-Supported Program for the Strategic Research Foundation at Private Universities (S1101034 and S1201038); a grant from the Promotion and Mutual Aid Corporation for Private Schools of Japan; a grant from the Japan Leukemia Research Foundation; a grant from the Mitsubishi Pharma Research Foundation; a grant from the Takeda Science Foundation; a grant from the Terumo Life Science Foundation and a grant from SENSHIN Medical Research Foundation. The authors are grateful to the Japanese Red Cross Kinki Cord Blood Bank for providing CB samples used in this study. Kyowa Hakko Kirin Company (Tokyo, Japan) is also acknowledged for providing the growth factors used in this study.

\section{Author contributions}

K.S. designed and performed a majority of the experiments and analyzed and interpreted the data; Y.M. designed and performed the experiments, analyzed and interpreted the data and contributed to the manuscript writing; H.K., R.N., T.F., provided study material and contributed to some parts of the experiments; H.A., provided advice on the statistical analyses; Y.T., contributed to the data analysis and interpretation; Y.S., conceived of and designed the study, analyzed and interpreted the data, provided financial and administrative support, and wrote the paper.

\section{Additional information}

Supplementary Information accompanies this paper at https://doi.org/10.1038/s41467018-04441-z.

Competing interests: The authors declare no competing interests.

Reprints and permission information is available online at http://npg.nature.com/ reprintsandpermissions/

Publisher's note: Springer Nature remains neutral with regard to jurisdictional claims in published maps and institutional affiliations. 
(c) (i) Open Access This article is licensed under a Creative Commons cc. Attribution 4.0 International License, which permits use, sharing, adaptation, distribution and reproduction in any medium or format, as long as you give appropriate credit to the original author(s) and the source, provide a link to the Creative Commons license, and indicate if changes were made. The images or other third party material in this article are included in the article's Creative Commons license, unless indicated otherwise in a credit line to the material. If material is not included in the article's Creative Commons license and your intended use is not permitted by statutory regulation or exceeds the permitted use, you will need to obtain permission directly from the copyright holder. To view a copy of this license, visit http://creativecommons.org/ licenses/by/4.0/.

(C) The Author(s) 2018 